J. comp. Physiol. 97, 215-243 (1975)

(C) by Springer-Verlag 1975

\title{
Effects of Maintained Depolarization of Presynaptic Neurons on Inhibitory Transmission in Lobster Neuropil ***
}

\author{
Donald M. Maynard*** and Kerry D. Walton \\ The Bermuda Biological Station for Research, Inc.; Department of Zoology, \\ University of Michigan, Ann Arbor; and Department of Biology, \\ University of Oregon, Eugene, USA
}

Received November 11, 1974

\begin{abstract}
Summary. 1. Intracellular microelectrode recordings were obtained from somata of the pre- and postsynaptic neurons of each of four neuron pairs in the stomatogastric ganglion of Panulirus argus. The microelectrodes were incorporated into a bridge circuit, permitting simultaneous recording and current passing.

The following cell pairs were investigated: I. Pyloric Dilator-Pyloric Neuron (PD—PY); II. Anterior Median-Gastric Neuron (AM-GM); III. Large EPSP-Lateral Cardiac or Posterior Gastro-pyloric (EX-LC/GP; IV. Large EPSP-Gastric Mill (EX-GM). The postsynaptic effects of current-induced variations in presynaptic membrane potential were studied in each neuxon pair under a variety of experimental conditions.

2. In two cell pairs, the PD-PY and the AM-GM, action potentials initiated antidromically in the presynaptic element did not evoke postsynaptic potentials. If the postsynaptic neuron was simultaneously depolarized through the soma electrode postsynaptic potentials were observed. It is suggested that in the normal functioning of the ganglion local presynaptic depolarizations as well as spikes contribute to transmitter release.

3. In the EX-GM and the EX-LC/GM cell pairs, presynaptic depolarization that did not initiate action potentials nevertheless evoked postsynaptic inhibition and hyperpolarization for as long as the presynaptic current was maintained. Control experiments showed that presynaptic hyperpolarization had no postsynaptic effect.

4. The hyperpolarizing effect of presynaptic depolarization could be blocked by picrotoxin in parallel with blockade of other IPSPs in the ganglion.

5 . The experimentally induced voltage changes in the presynaptic terminals are probably comparable to those resulting from synaptic input to the neuron. These experiments support the hypothesis that, in life, depolarization of presynaptic terminals that are subthreshold for action potentials may facilitate or eroke transmitter release. Such presynaptic, nonspike potentials may play a significant role in the modulation of synaptic transmission in neuropil.
\end{abstract}

\section{Introduction}

Intracellular recordings from most neurons of the CNS of arthropods show extensive local synaptic and generator potential activity (Maynard, 1966; Bentley, 1969; Kennedy and Preston, 1960). It has generally been assumed that except for weak field effects and interaction via low resistance electrical junctions these potentials act on other elements of the neuropil by initiating propagated action potentials which in turn trigger transmitter release at synaptic junctions. That postsynaptic potentials may also affect transmitter release without producing

* Send reprint requests to: Dr. E. Maynard, Biology Department, University of Oregon, Eugene, Oregon 97403, USA

** Contribution No. 608 from the Bermuda Biological Station, St. George's West, Bermuda. *** Dr. Maynard died in January, 1973. This paper was prepared by K.D.W. from a draft available at that time. 
action potentials has been recognized in the special cases of presynaptic inhibition (Schmidt, 1971) and facilitation (Dudel and Kuffler, 1961). Studies of retinal elements also suggest that transmitter release in the vertebrate retina (Werblin and Dowling, 1969) and insect ocellar (Chappell and Dowling, 1972) and compound (Bauman, 1968) retinas must be controlled by slow, non-spike potentials. Few experiments, however, have tested the possibility that transmitter release in neuropil may depend upon both propagated, all-or-none action potentials and local, graded potentials.

During an investigation of neural integration in the stomatogastric ganglion of lobsters, we found several instances in which unitary inhibitory postsynaptic potentials produced by spikes were augmented by simultaneous polarization of the soma of the presynaptic neuron. Indeed, one cell type, upon somatic depolarization, produced hyperpolarization in postjunctional neurons without intervening action potentials. These phenomena, if found generally in neuropil, may be important in neural integration.

\section{Methods}

Adult spiny lobsters, Panulirus argus, were used for the illustrated experiments. After appendages were removed and the animal was bled through an incision between thorax and abdomen, the carapace was opened and the stomach removed. The stomach was slit ventrally and washed thoroughly with perfusion fluid (see below) to remove digestive juices, and spread in a dissecting dish. The stomatogastric ganglion (which lies in the aorta on the dorsal, anterior surface of the stomach) was exposed together with associated nerves. The ganglion was dissected free of muscle, blood vessels, and connective tissue and placed in a recording chamber on a layer of resin (Sylgard 184; Dow Corning Corp., Midland, Mich.). The ganglion was pinned in place through remnants of the arterial wall and the nerves spread over the surface of the resin. The entire isolated preparation was covered with perfusion fluid to a depth of 1-5 $\mathrm{mm}$ and the dorsal surface of the stomatogastric ganglion was desheathed. Platinum wire electrodes for external recording were inserted in pairs into the resin alongside appropriate nerves, the electrodes and associated region of the nerve were then covered with petrolatum for insulation. These electrodes were also used for stimulation. This method permitted the use of a large number of simultaneous recording/stimulating sites (often 15 or 16) in a single preparation. Even the smallest nerves containing only one or two axons usually remained in good condition over the several hours of the typical experiment. Fig. 1 diagrams an isolated preparation with external electrodes in place. The time required to set up such a preparation from initial cut to first recording normally ranged between 6 and 8 hours.

Glass capillary microelectrodes filled with either $3 \mathrm{M} \mathrm{KCl}$ or $0.5 \mathrm{M} \mathrm{K}_{2} \mathrm{SO}_{4}$, with resistances between 10 and 30 megohm, were used for intracellular recording. In one experiment Bioelectric Instruments NF1 preamplifiers with a conventional external bridge for simultaneous stimulation were used; in others W-P Instrument 4 or $4 \mathrm{~A}$ amplifiers with a built-in stimulating circuit were employed. Recorded activity was displayed conventionally on a Tektronix 565 CRO with multiple-trace plug-in amplifiers and photographed with a Grass C4 camera or recorded on an Ampex FR-1300 FM tape-recorder at 7-1/2 ips for later analysis. Grass S4K and S88 stimulators and P51.F preamplifiers for extracellular potentials were used.

The perfusion solution, derived from measurements of the ionic concentrations in the blood of Panulirus argus by Diane Mathias, contained $521.2 \mathrm{mM} \mathrm{Na} ; 10 \mathrm{mM} \mathrm{K} ; 16.7 \mathrm{mM}$. $\mathrm{Ca} ; 16.7 \mathrm{mM} \mathrm{Mg} ; 566.6 \mathrm{mM} \mathrm{Cl} ; 20.7 \mathrm{mM} \mathrm{SO}$, and in addition was buffered to $\mathrm{pH} \mathrm{7.4-7.8}$ with 10 ce $0.5 \mathrm{M}$ boric acid-sodium hydroxide buffer or "Trisma" buffer per liter solution. Preparations routinely remained in good condition for at least 16 hours. Earlier experiments using modified Homarus perfusion solution (Cole, 1941) also gave satisfactory results.

In some preparations, solutions of L-glutamate, gamma-amino butyric acid (GABA), and picrotoxin (Nutritional Biochemical Co.) in perfusion were applied to the whole ganglion. 
For such experiments a chamber containing about $0.5 \mathrm{ml}$ was placed around the ganglion, isolating it from the major portion of the nerve branches. The enclosed ganglion was then continuously superfused at rates between 3 and $5 \mathrm{ml} / \mathrm{min}$ with saline or the various test solutions. The picrotoxin was normally applied for 5-7 min.

The experiments at the University of Michigan and the University of Oregon were performed with animals provided by S. Becker of Tropical Atlantic Marine Specimens. The remaining experiments were performed at the Bermuda Biological Station with local animals. The temperature at Michigan and Oregon was $15.5^{\circ} \mathrm{C}$, and at Bermuda ranged between 22.5 and $23.4^{\circ} \mathrm{C}$.

\section{Results}

The stomatogastric ganglion in Panulirus closely resembles that of the crayfish described by Orlov (1927). It is oval, and covered by a dorsal rind of large, monopolar cell bodies whose processes descend into the neuropil where they ramify extensively before sending axons out to the striated stomach muscles (Maynard and Dando, 1974). Fig. 2 is a photograph of a desheathed ganglion. Note the obvious cell bodies, which in this ganglion vary from 27 to 31 in number. Somata in a 1-2 kg lobster may be as large as $100 \mu$ in diameter, as measured in fixed, sectioned preparations. One, or possibly two, of the ganglion neurons are probably sensory neurons whose axons pass through the ganglion without functional connections and travel anteriorly to the CNS (see Orlov, 1927; Larimer and Kennedy, 1966). Most of the remaining cells of the ganglion are motor neurons that send axons into the stomach musculature where they terminate on specific muscles. Each neuron innervates comparable muscles on both right and left sides of the stomach, and thus wherever bilaterally paired muscles occur, axons divide and one branch runs to each muscle. All motor axons thus far identified are excitatory in the muscle, evoking depolarizing junction potentials and contraction. In the ganglion the motor neurons form synaptic connections among themselves (Atwood and Maynard, 1969), most of which are inhibitory. The ganglion receives both excitatory and inhibitory input from interneurons whose somata lie elsewhere in the CNS.

Most of the muscles of the stomach are innervated by a small number of neurons, often only one or two (Maynard and Dando, 1974). Where multiple innervation occurs, the characteristics of the several neurons involved tend to be similar. Neurons in the ganglion are identified according to the muscles they innervate. In the isolated preparation, terminal or near terminal nerve branches containing axons innervating a single muscle were identified. Neurons whose cell bodies were penetrated in the ganglion were thus recognized by their properties or activity patterns, by action potentials recorded simultaneously in an identified peripheral nerve axon, or by antidromic potentials initiated in known terminal nerve branches. It should be emphasized that in favorable preparations the entire propagated spike output of the ganglion may be monitored by appropriate placement and selection of extracellular electrode pairs.

Microelectrodes placed in the cell bodies of the stomatogastric neurons recorded spike potentials, synaptic potentials, and slow potentials. The spike potentials never overshot the resting potential, and normally ranged in amplitude from 10 to $20 \mathrm{mV}$, suggesting that they did not invade the cell body. Spike potentials evoked by current injected through the penetrating electrode did not differ ob- 


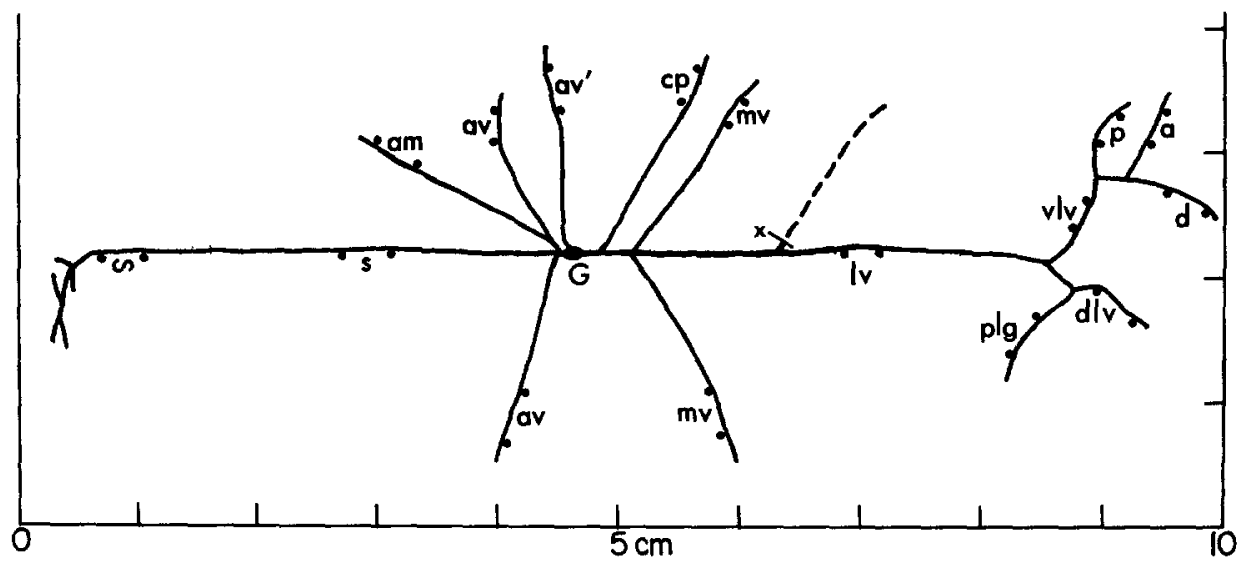

Fig. 1. Stomatogastric ganglion and associated nerves in recording chamber (traced to scale). Paired dots $(\cdots)$ represent exact locations of platinum wires for extracellular recording and stimulation on the following nerves: $a$ ampullary, am anterior median, $a v$ anterior ventricular (right and left), $a v^{\prime}$ anterior ventricular, posterior branch in this preparation; $c p$ cardiopyloric, $d$ ventral pyloric dilator, $d i v$ dorsal lateral ventricular, $l v$ lateral ventricular (right lateral ventricular is cut at " $\mathrm{x}$ "), $m v$ median ventricular, $p$ pyloric, $p l g$ posterior lateral gastric, $s$ stomatogastric, $v l v$ ventral lateral ventricular, $v$ stimulating electrodes on stomatogastric nerve. $G$ refers to the stomatogastric ganglion itself

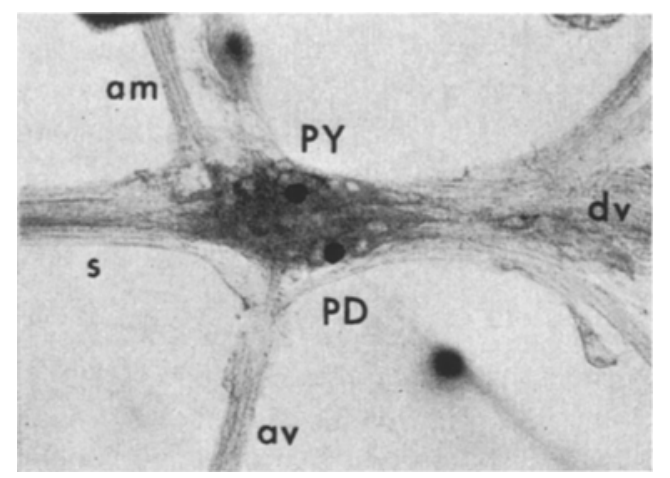

Fig. 2. Desheathed stomatogastric ganglion in recording chamber, dorsal view. Two cells (PY and PD) penetrated with microelectrodes are blacked in. Microelectrodes are out of focus, but points of entry into meniscus of fluid covering ganglion are evident as dark spots above and to the left of PY and below and to the right of PD. am anterior median nerve (unpaired), $a v$ anterior ventricular nerve (paired), $d v$ dorsal ventricular nerve (unpaired), $s$ stomatogastric nerve (unpaired)

viously from spontaneous or synaptically evoked impulses. Synaptic potentials varied in amplitude and time course. Most of them apparently originated some distance from the cell body in the underlying neuropil (Orlov, 1927; Maynard and Burke, 1966; Maynard, 1969). Although the electrodes in the cell body of the ganglion neurons record much of the significant electrical activity of the neu- 
ron, they must be considered distant from most synapses and therefore record synaptic potentials which are attenuated in quantitatively unknown ways.

All stomatogastric neurons thus far penetrated make effective connections with other neurons in the ganglion. This paper considers several instances where transmission between identified neurons in the ganglion is facilitated by somatic depolarization of the prejunctional element. We will not consider many of the problems of synaptic connectivity with other elements or questions associated with patterning of ganglionic activity except where necessary for interpretation.

Most motor neurons of the stomatogastric ganglion fall into one of two functional groups, those elements producing the pyloric rhythm and those producing the gastric mill rhythm (Maynard and Burke, 1966; Maynard, 1972; Morris and Maynard, 1970; Mulloney and Selverston, 1974a, b; Selverston and Mulloney, 1974; Powers, 1973). Neurons can be assigned to the appropriate group on the basis of the muscles they innervate, their synaptic connections in the ganglion, and their major discharge pattern. Of the four neuron pairs considered here, one involves members of the pyloric group and the other three involve members of the gastric mill system. We will consider the pair involved in the pyloric rhythm first.

\section{Pyloric Dilator Neuron-Pyloric Neuron (PD-PY Pair)}

The first member of this pair, the PD or pyloric dilator neuron, belongs to a subgroup of two electrically coupled neurons with essentially identical properties. They innervate the dorsal and central pyloric dilator muscles. The PD neurons are electrically coupled to the anterior burster (AB) and ventral dilator (VD) neurons. The second member, the PY or pyloric neuron, belongs to a subgroup of 8 electrically coupled neurons which innervate various intrinsic muscles.

During one phase of normal pyloric activity, the PD neurons discharge in rhythmic bursts of impulses arising from underlying slow potential oscillations whose amplitude may reach several millivolts (up to $15 \mathrm{mV}$ ) as recorded in the soma. The PY neurons are inhibited during such bursts. Although each of the four coupled neurons (the $2 \mathrm{PD}$ elements, one $\mathrm{AB}$ neuron, one VD neuron) (Maynard, 1972) produces hyperpolarizing potentials in PY cells, this paper will consider in detail only those inhibitory postsynaptic potentials (IPSPs) elicited by the PD neurons.

Figs. 3 and 4 illustrate IPSPs in the PY neurons evoked by single action potentials in each PD neuron. The PD spikes were initiated in the penetrated PD neuron and its twin by current applied through the recording electrodes. Extracellular controls indicate that the AB and VD neurons were not activated at this level of current. Since the PD-evoked IPSPs can be reversed in sign by hyperpolarizing currents in the postsynaptic PY elements, it is likely that they represent conductance changes induced by an inhibitory transmitter.

Both the apparent latency and rise time of these IPSPs are longer $(45 \mathrm{msec}$ latency, 80 msec rise time are typical values) than those evoked in the same PY neuron by other presynaptic elements (see Figs. 3B and 5) which may have latencies of the order of 2-5 msec and rise times of $15 \mathrm{msec}$. These IPSPs follow PD neuron impulses in a $1: 1$ fashion without significant change in latency over 

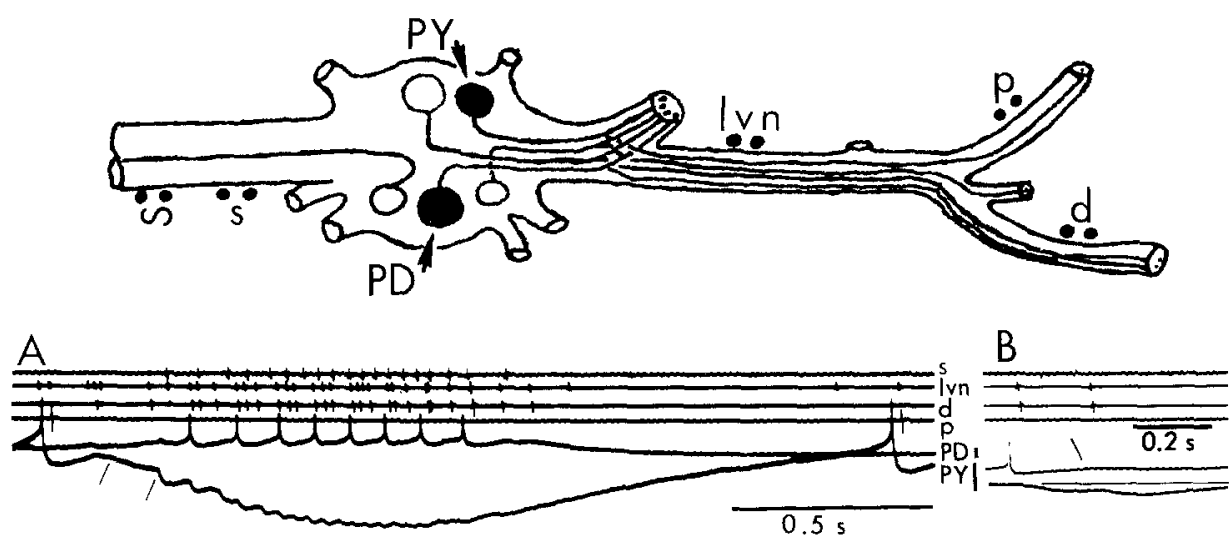

Fig. $3 \mathrm{~A}$ and $\mathrm{B}$. Pair I. Interaction between PD and PY neurons

Inset: Diagram of extracellular stimulating $(\omega)$ and recording electrodes $(s, l v n, d$, and $p)$. Axon paths of penetrated neurons PD and PY (filled cells) and unpenetrated elements PL, $\mathrm{PD}^{\prime}$, and $\mathrm{AB}$ whose activity was recorded in the above traces (unfilled circles) are also shown (see also Fig. 1).

(A) Spontaneous burst of PD neurons. Intracellular recordings from PD and PY neurons and extracellular recordings from four nerves (see inset): $s$ stomatogastric nerve, $l v n$ lateral ventricular nerve, $d$ ventral pyloric dilator nerve, $p$ pyloric nerve. PY neuron slightly depolarized with injected current through recording electrode. Spikes in " $\mathrm{s}$ " trace arise in AB neuron in ganglion and produce IPSPs (second hatch mark) in PY neuron and transient depolarization in PD. Spikes in "Irn" trace originate in both PD neurons, the PY neuron, the LP neuron (lateral pyloric), and other axons passing backward from the ganglion. Spikes in " $d$ " trace originate in LP neuron, in the unpenetrated $\mathrm{PD}^{\prime}$ neuron, and in the penetrated PD neuron. LP impulses evoke IPSPs in both the PD neuron and the PY neuron; PD impulses evoke slow IPSP in the PY neuron (first hatch mark). Spikes in "p" trace originate in the penetrated PY neuron.

(B) Slow IPSP produced by PD neurons. PD neuron depolarized to produce spikes, PY neuron slightly depolarized to emphasize IPSP. Note long delay (about $45 \mathrm{msec}$ ) and slow rise time of IPSP in PY neuron. Impulse in nonpenetrated PD neurons evokes transient depolarization in other PD element (hatch mark) and a second IPSP in PY neuron. Intracellular scale; PD $10 \mathrm{mV}$, PY $5 \mathrm{mV}$. Reference line added

a wide range of frequencies. Although such IPSPs may not always be evident following PD spikes in all preparations and at all times (see below), they have never been observed in the absence of PD action potentials, nor have they suddenly disappeared or appeared intermittently during a train of $\mathrm{PD}$ impulses. Except for their unusually long latency, these IPSPs have all the characteristics found in monosynaptic junctions. Other observations, such as the complete absence in the more than 100 preparations studied of any intracellular or extracellular activity which could be ascribed to an interneuron discharging between the PD spike and the IPSP in the PY neuron, and the evidence from summating IPSPs that at least four independent interneurons would be required (one for each of the four coupled elements which inhibit PY neurons with long IPSPs), support the assumption of monosynaptic junctions between the PD and PY elements. Obviously these data do not exclude the possibility of an interelement 

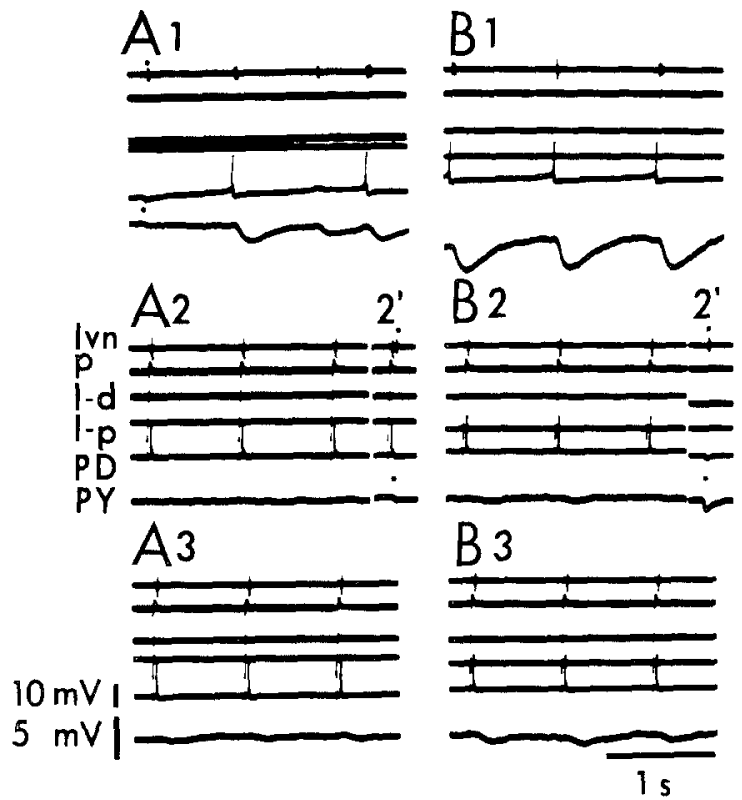

Fig. 4
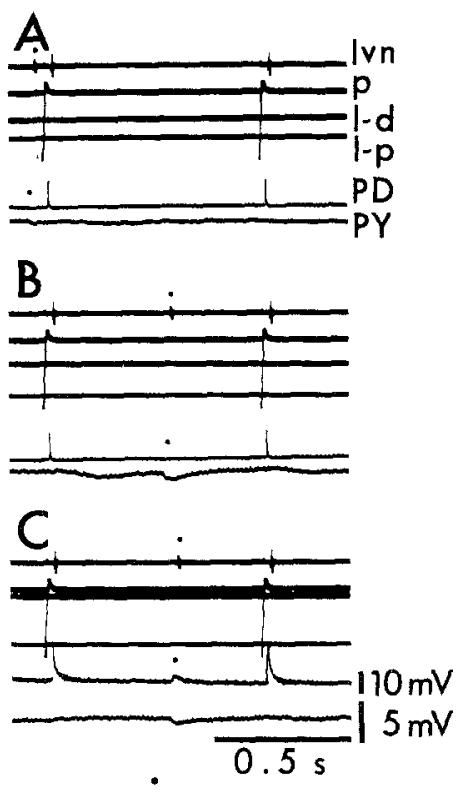

Fig. 5

Fig. 4A and B. Pair I. Interaction between PD and PY neurons

(A) Effects of PD depolarization on IPSP in PY neuron. 1) PD neuron depolarized, with injected current (1.2 nA) evoking two near simultaneous impulses in the two PD elements and an isolated impulse in the nonpenetrated $\mathrm{PD}^{\prime}$ neuron. IPSPs in the PY neuron are of reasonable amplitude and show spatial summation. Traces as indicated in Fig. 3. 2) PD axons are stimulated at "d" electrode pair (see Fig. 3), evoking antidromic impulses in both PD neurons (frequency about $1 / \mathrm{sec}$ ). IPSPs in the PY neuron are not evident. $2^{\prime}$ ) The LP neuron occasionally discharged spontaneously, producing an impulse in the "lvn" trace and an IPSP in the PY and PD neurons. These are identified by dots and are included for comparison with the IPSPs produced by the PD neurons. 3) Antidromic stimulation of PD neuron axons combined with depolarization of PD cell body with injected current $(0.7 \mathrm{nA})$. IPSPs in the PY neuron, though small, are evident.

(B) Effects of PD depolarization on IPSPs as in Fig. 4A but with PY neuron depolarized with injected current $(1 \mathrm{nA})$ to emphasize IPSPs. Traces 3 and 4 in $A$ and B represent current monitors for the penetrated PD neuron (I-d) and the PY neuron (I-p)

Fig. 5A-C. Pair I. Effects of PD hyperpolarization and PY depolarization on IPSP in PY neuron. In all records, antidromic impulses were produced in the two PD neurons by stimulation of the "d" electrode pair on the ventral pyloric dilator nerve (see Figs. 1 and 3, "d").

Impulses in the LP netron, together with evoked IPSP, are indicated by dots (•)

(A) Antidromic PD stimulation only, no cellular polarization. I-d, eurrent monitor for PD neuron; I-p, current monitor for PY neuron; lvn recording from lateral ventricular nerve (see Fig. 3); $p$ recording from pyloric nerve; PD, pyloric dilator neuron, intracellular recording; PY, pyloric neuron, intracellular recording.

(B) Antidromic PD stimulation, PY depolarized with 1.4 nA current. IPSPs evoked by $\mathrm{PL}$ and $\mathrm{PD}$ neurons are augmented.

(C) Antidromic PD stimulation, PY depolarization, and PD hyperpolarization with $8 \mathrm{nA}$ current. Antidromic impulses are augmented, and IPSP in PD neuron evoked by LP is changed in sign and increased in amplitude. IPSP in PY neuron evoked by LP is unchanged, but IPSPs evoked by $P D$ neuron are not evident 
which does not produce propagated spikes or is locally attenuated, but the observations can be more simply explained by assuming either slow transmitter release from the presynaptic terminals and/or slow postsynaptic membrane response together with a relatively distant location on the PY neuron arborizations.

There is no evidence that the PY neurons synapse upon or otherwise directly affect the $\mathrm{PD}$ elements.

Fig. 4A and $\mathrm{B}$ illustrate the aspect of PD-PY neuron interaction considered in this paper. Orthrodromic PD spikes initiated by depolarization of the soma evoked IPSPs in the postsynaptic PY neuron that were typically $10 \mathrm{mV}$ in amplitude (Fig. 3A). When both PD neurons discharged together, the amplitude of the resulting IPSP in the PY neuron approximated the summed amplitude of the two IPSPs produced separately (Fig. 4A1). However, antidromic impulses in the PD neurons, elicited by stimulation of a nerve branch containing only the two PD neuron axons, evoked IPSPs which were $<1 \mathrm{mV}$ in amplitude (Fig. 4A2 and 4B2). The antidromic action potential recorded in the PD neuron soma differed from that evoked by soma depolarization only in the absence of the generator potential and post-spike hyperpolarization.

The relative ineffectiveness of antidromic spikes in evoking IPSPs when compared with orthodromic spikes elicited by artificial soma depolarization or by slow depolarizations during spontaneous bursts suggests that transmitter release may be facilitated by maintained subthreshold depolarization of presynaptic arborizations in the neuropil of the stomatogastric ganglion. If so, then:

1. Depolarization of the PD neuron soma should increase the amplitude of IPSPs in the PY neuron evoked by antidromic PD neuron action potentials.

2. Hyperpolarization of the PD neuron should reduce the amplitude of such IPSPs.

3. Depolarization of the PD neuron at levels below spike threshold should increase the rate of spontaneous release of the inhibitory transmitter. In the absence of detectable miniature IPSPs, such release during PD neuron depolarization might be signalled by depression of repetitive PY neuron discharge and/or by hyperpolarization of the postsynaptic PY neuron membrane.

Figs. 4A3, 4B3, 5 and 6 show that the results of experiments testing the above predictions in this preparation are in accord with the hypothesis that nonspike depolarization of the presynaptic neuron (and by implication, presynaptic terminals) augments release of inhibitory transmitter.

When the penetrated PD neuron was depolarized during antidromic stimulation with injected current $(0.7 \mathrm{nA})$ which by itself was insufficient to produce spikes, amplitude of IPSPs evoked by the antidromic impulses was augmented (Fig. 4A3 and 4B3).

In another experiment with the same ganglion, IPSPs evoked by antidromic PD neuron impulses remained undetectable until the postsynaptic PY neuron was depolarized (1.4 nA, compare Fig. 5A and 5B). When the PD presynaptic neuron was then hyperpolarized, the IPSPs following antidromic impulses were reduced or rendered undetectable, even though the amplitude of the recorded presynaptic action potential was augmented (Fig. 5C). Fast IPSPs in the PY neuron 


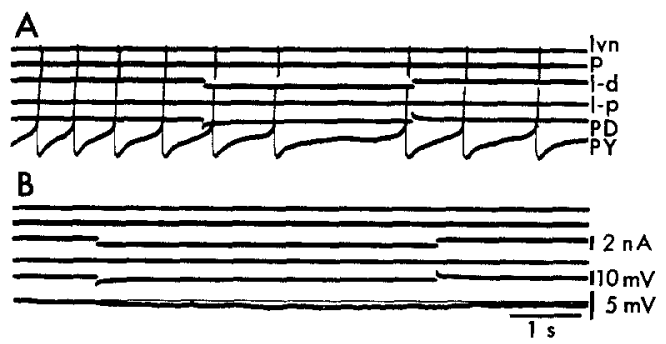

Fig. 6A and B. Pair I. Effects of subthreshold depolarization of PD neuron on PY activity. $A$ and $B$ are two segments of a continuous record taken about 7 sec apart

(A) Effects on repetitive discharge in PY neuron. Recording begins shortly after initiation of discharges in the PY neuron evoked by $1 \mathrm{nA}$ depolarizing current. A three second depolarizing current pulse $(0.8 \mathrm{nA})$ in the PD neuron (third and fifth traces) reduces the frequency of discharge. $I$ - $d$ current monitor of PD neuron, $I$ - $p$ current monitor of PY neuron, $l v n$ lateral ventricular nerve, $p$ pyloric nerve, $P D$ intracellular recording from $P D$ neuron, $P Y$ intracellular recording from PY neuron.

(B) Effects on membrane potential. Recording taken several seconds after initiation of depolarizing current in PY neuron (see above) and after complete adaptation of repetitive discharge. Subthreshold depolarizing current in PD neuron $(0.8 \mathrm{nA})$ produces small maintained hyperpolarization in PY neuron. Reference line added. Records in Figs. 3-6 were taken from one preparation

evoked by another presynaptic neuron (the LP or lateral pyloric neuron) were unaffected by PD neuron polarization, indicating that the observed changes of the slow IPSPs probably were not caused by spread of hyperpolarizing current from PD to PY elements or any other non-synaptic effect on the postsynaptic element.

Finally, the frequency of repetitive spikes in the postsynaptic PY neuron, elicited by depolarizing current injected through the penetrating electrode, was slowed when the synaptic PD neuron was simultaneously depolarized with currents subthreshold for spikes $(0.8 \mathrm{nA})$ (Fig. 6). Variation in the membrane potential associated with the repetitive discharge prohibited reliable detection of possible hyperpolarization associated with such depression, and so depolarizing current flow was maintained in the postsynaptic (PY) element until complete inhibition occurred, and no further spikes were generated. Depolarization of the presynaptic PD neuron at that time produced slight hyperpolarization (Fig. 6B). When the electrode was removed from the PD neuron, similar or greater currents had no significant effect on PY neuron activity or membrane potential.

These experiments indicating an inhibitory effect of presynaptic depolarization without action potentials favor the hypothesis that such depolarization in some way directly facilitates transmitter release at the presynaptic terminals, and makes an alternative mechanism-facilitation of action potential spread into effective presynaptic terminals-less attractive as the sole explanation of the observations illustrated. Facilitation fails to explain the results in Fig. $6 \mathrm{~A}$. Depolarization of the PD neuron that is insufficient to evoke a spike nevertheless decreases the spiking frequency of the PY neuron. Thus, inhibition of the postsynaptic cell occurs in the absence of a presynaptic spike. The results also appear 
to be sufficient to render another alternative-spread of depolarizing current from pre- to postsynaptic membrane with corresponding increase in IPSP amplitude-completely unacceptable. Our experiments, therefore, strengthen the argument that augmentation of IPSPs by PD neuron depolarization involves a presynaptic mechanism; an increased release of transmitter that can be brought about without intervening action potentials,

The actual presynaptic terminal potential changes necessary to facilitate transmission can only be approximated since imbalance of the bridge circuit prevented accurate estimates of this neuron's effective resistance, and distance from the soma to the terminals is unknown. Membrane resistance measured in a number of other PD neurons of similar size ranged from 5 to 10 megohms. In this preparation, the effective presynaptic depolarizing current varied between 0.8 and $6 \mathrm{nA}$. Thus, the induced polarizations were about $4-60 \mathrm{mV}$ at the soma, 1.5-22 $\mathrm{mV}$ at a distance of one space constant, and still less at terminations of more distant processes. The amplitude of the normal slow PD neuron burst depolarization-which may be presumed to originate some distance away in neuropil arborizations and to decrement as it spreads to the recording electrode in the soma-was $10 \mathrm{mV}$ in this preparation. Therefore, even though terminal potential changes (produced by injected current) that were effective in modulating IPSPs cannot be estimated accurately, it is clear that they were of the same order of magnitude as those associated with normal, slow potential oscillations in the PD neuron.

\section{Anterior Median Neuron-Gastric Mill Neuron (AM-GM Pair)}

The AM neuron innervates the muscle network spread over the anterior surface of the cardiac stomach. The GMI neuron is one of four electrically coupled neurons which innervate the extrinsic anterior and posterior gastric muscles.

Depolarization of the AM neuron evokes a maintained spike discharge and inhibition of ongoing activity in the four GM neurons (see Fig. 7A). Fig. 7B was made after penetration of one of the GM neurons. Two kinds of IPSPs are evident in the GM neuron record. One is produced by a spontaneous active element (the CI neuron, or Interneuron I [Mulloney and Selverston, 1974a]), whose impulses originate in the ganglion and, after evoking IPSPs in GM neurons, propagate anteriorly in an axon of the stomatogastric nerve (Fig. $7 \mathrm{~B}$, trace 6). The second kind of IPSP is the one of interest here. It has a similar time course, and summates with the first, but is produced by action potentials evoked in the

Fig. $7 \mathrm{~A}-\mathrm{C}$. Interaction between AM and GM neurons (Pair II)

Inset: Diagram of ganglion and nerves showing relative location of GM and AM neuron soma (taken from freehand sketch of experimental preparation) in ganglion, course of their axons, and location of extracellular stimulating and recording electrodes. am anterior median nerve, $a v$ anterior ventricular nerve, $d$ ventral pyloric dilator nerve, $p l g$ posterior lateral gastric nerve, $s$ stomatogastric nerve, $\omega$ stimulating electrodes on stomatogastric nerve.

(A) Inhibitory effects of AM neuron discharge evoked by depolarizing current. Only the AM neuron was penetrated in this record. It was quiescent until depolarized with $4.4 \mathrm{nA}$. It then discharged repetitively (traces AM and am) inhibiting spikes from four GM neurons in trace "av" and two LG neurons in trace "plg". There was no effect on the pyloric burst (trace s). 

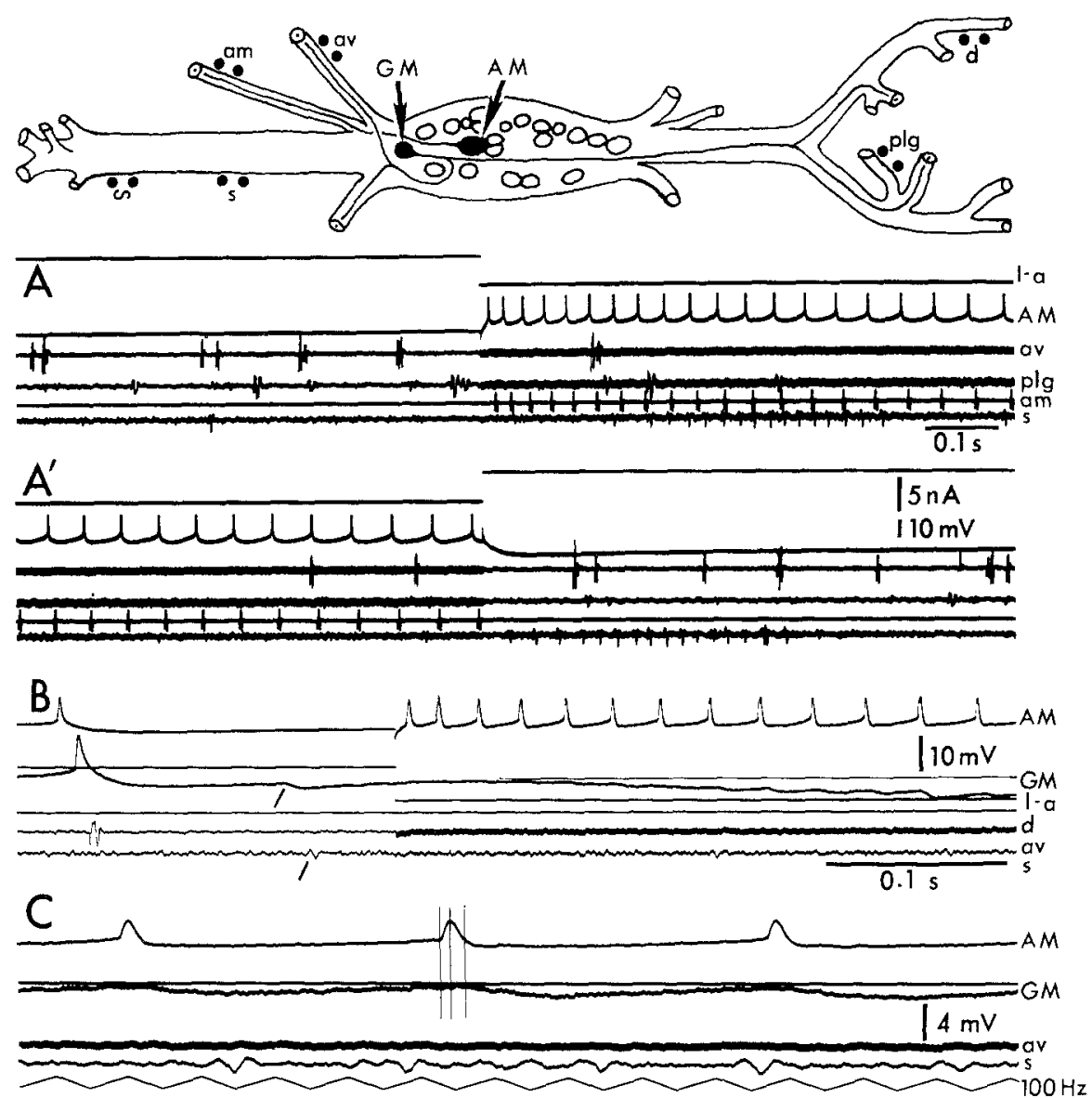

Fig. 7

(A') Direct continuation of record A. Upon cessation of depolarizing current, ongoing discharge in GM and LG neurons returns. Traces: $I$ - $a$ current monitor for AM neuron, $A M$ intracellular recording from AM neuron, $a v$ anterior ventricular nerve containing axons of GM neurons, plg posterior lateral gastric nerve, am anterior median nerve containing axon of AM neuron, $s$ stomatogastric nerve.

(B) Inhibitory effects of AM neuron on GM neuron. With depolarizing current ( $5 \mathrm{nA})$, the AVI neuron discharges repetitively, each action potential after the first evoking a visible IPSP in the penetrated GM neuron. IPSP exhibited both facilitation-growth of amplitude of succeeding IPSP-and temporal summation. Hatch marks indicate IPSP evoked by an impulse in CI neuron (trace GM) and CI action potential in stomatogastric nerve. $G M$ intracellular record from one of GM neurons (note extracellular action potential of this unit recorded in $a v$ trace), $d$ ventral pyloric dilator nerve. Other traces as indicated in Fig. $7 \mathrm{~A}$.

(C) Latency of GM neuron IPSP. AM neuron depolarized to produce repetitive discharges; simultaneous intracellular recording from postsynaptic GM neuron. Rise time of impulse in AM neuron, about $1.5 \mathrm{msec}$; time from peak of impulse in AM neuron to beginning of IPSP in GM neuron, about 2.1 msec.

Recording/stimulating intracellular electrode was not always balanced, so apparent DC shift with injected current is not accurate. Calibration, $10 \mathrm{mV}$, in $\left(A^{\prime}\right)$ applies to all intracellular recordings from AM neuron. Calibration in (B) applies to GM neuron in (B) only, and calibration in (C) applies to GM neuron in (C) only. Reference lines added 
AM neuron by soma depolarization. It is evident from Fig. $7 \mathrm{~B}$ that this IPSP exhibits both facilitation and summation at impulse frequencies of $38 \mathrm{~Hz}$. Fig. $7 \mathrm{C}$ shows that the latency from AM neuron action potential peak to beginning of GM neuron IPSP lies between 1.8 and $2.5 \mathrm{msec}$, and this together with a strict 1:1 correspondence over a variety of frequencies and the absence of observed interneuron spikes strongly suggests a monosynaptic junction between the AM and the GM neurons. The AM-GM junction is polarized; neither action potentials in the postsynaptic GM neuron nor positive and negative potential shifts caused by injected current produced detectable effects on the presynaptic AM neuron.

Fig. 8 shows that, as with the PD-PY pair, the effectiveness of AM neuron spikes in evoking IPSPs in the GM neuron is related to the membrane potential of the presynaptic element. Under normal conditions (Fig. 8 A) the AM neuron discharges occasionally while an ongoing spike discharge in the GM unit is super. imposed upon a background of repetitive IPSPs produced by the CI neuron. When the AM neuron is depolarized sufficiently (Fig. 8B), it discharges repeti. tively, evoking IPSPs in the GM neuron which summate with each other and with the CI-evoked IPSPs, suppressing the ongoing GM spike discharge and producing a net hyperpolarization of the GM neuron. When the AM neuron is activated antidromically by repetitive stimulation of its solitary axon in the anterior median nerve, spike potentials evident in the intracellular record fail to evoke observable IPSPs in the GM neuron (Fig. 8C) and the latter's spike discharge continues unabated. Hyperpolarization of the AM neuron augments the amplitude of the recorded action potential, but has little or no effect on the GM neuron discharge (Figs. 8D and 9). Depolarization of the AM neuron during antidromic activity, however, results in IPSPs of a few $\mathrm{mV}$ in the GM neuron and inhibition of its discharge (Fig. 8E).

Figs. 9 and 10 show that increasing depolarizations of the AM soma produce a continuously graded inhibition of the GM neuron. In Fig. 9 the relative GM discharge frequency during antidromic stimulation of the $\mathrm{AM}$ neuron at $21 \mathrm{~Hz}$ is expressed as a function of the change in recorded membrane potential of the AM neuron produced by injected current. The electrode in this preparation was well balanced and stable (see Fig. 8), and the I-V plot was essentially linear over the range used. It is evident that the GM discharge frequency was progressively slowed as the membrane potential of the AM soma increased from the normal resting level to about $15 \mathrm{mV}$ depolarization, when all GM spikes ceased. The effect of AM depolarization over greater ranges is illustrated in Fig. 10. Short samples taken at about $0.6 \mathrm{sec}$ intervals during a continuously varying depolarizing current are joined. The upper trace monitors the depolarizing current, the second trace records the activity of the $A M$ neuron, and the third trace records GM activity. It is likely that the linear range of the current-recording electrode in the AM neuron was exceeded, and that the membrane potential change is accordingly unreliable. Nevertheless, the summed hyperpolarization of the GM neuron during constant-frequency antidromic impulses in the AM neuron was roughly proportional to the depolarizing current in the AM neuron.

Since the AM neuron was close to spike threshold in its resting state, depolarization always evoked action potentials (except during antidromic stimulation) 


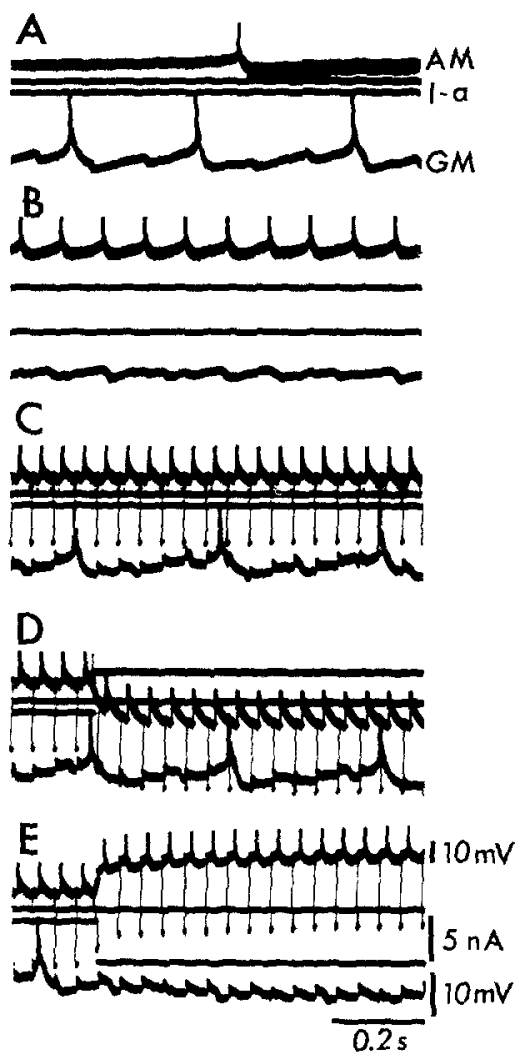

Fig. 8A-E. Pair II. Effects of AM neuron membrane potential on synaptic transmission. Simultaneous intracellular recording from AM neuron (trace AM) and GM neuron (trace GM).

Monitor of applied current in AM neuron indicated in third trace (I-a)

(A) Normal activity, unstimulated preparation. Decasional action potential in AM neuron does not produce obvious IPSP in GM neuron. GM neuron receives continuous bombardment from CI neuron as indicated by regularly spaced ongoing IPSPs. GM neuron also discharges repetitively.

(B) Depolarization of AMI neuron evokes repetitive spike discharge (11 $\mathrm{Hz})$ in AM neuron and IPSPs and inhibition in the GM neuron. Each AM neuron potential evokes an IPSP in the GM neuron which summates with the CI neuron IPSPs and with preceding AM neuron IPSPs to maintain hyperpolarization.

(C) Antidromic stimulation of AM neuron at $21 \mathrm{~Hz}$ at "am" electrode pair (Fig. 7), no depolarization of AM neuron. Antidromic action potentials are recorded in AM neuron but elicit no inhibition and no IPSPs in GM neuron. Stimulus artifacts are obvious in the AM and GM traces.

(D) Antidromic stimulation of AM neuron combined with hyperpolarizing current $(5 \mathrm{nA})$. Amplitude of antidromic action potentials in AM neuron increases but there is no evidence of inhibition or evoked IPSPs in the GM neuron.

(E) Antidromic stimulation of AM neuron combined with depolarizing current (5 nA). With AM depolarization, inhibition and AM neuron IPSPs become evident in GM neuron. Stimulus artifacts in GM trace obscure IPSPs.

Recording/stimulating electrode balanced in these records so voltage change in AM neuron closely approximates true effect of injected current 


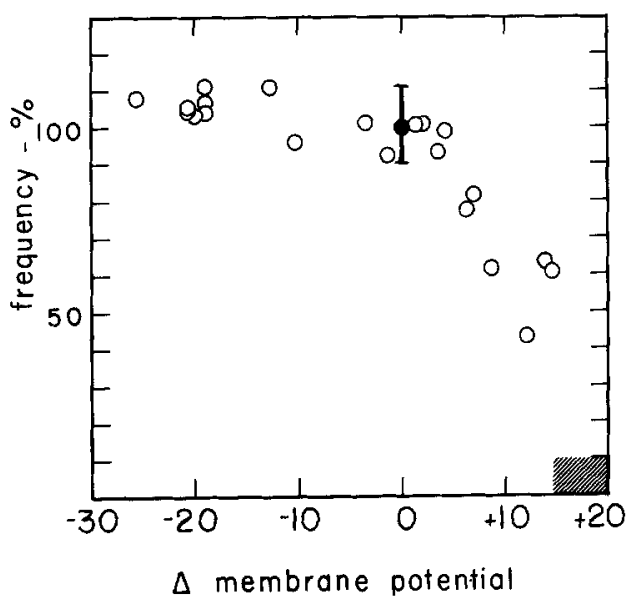

Fig. 9. Pair II. Effect of presynaptic membrane potential (AM neuron) on inhibition of postsynaptic repetitive discharge (GM neuron) by antidromic presynaptic impulses. Data taken from records similar to those illustrated in Fig. 8. Ordinate, frequency of discharge of postsynaptic GM neuron, $100 \%=3.2 / \mathrm{sec}$; abscissa, membrane potential change in $\mathrm{m} \nabla$ of presynaptic AM neuron produced by applied current during antidromic stimulation at $21 \mathrm{~Hz}$. Shaded area beyond $-15 \mathrm{mV}$ indicates region where all ongoing postsynaptic impulses become inhibited

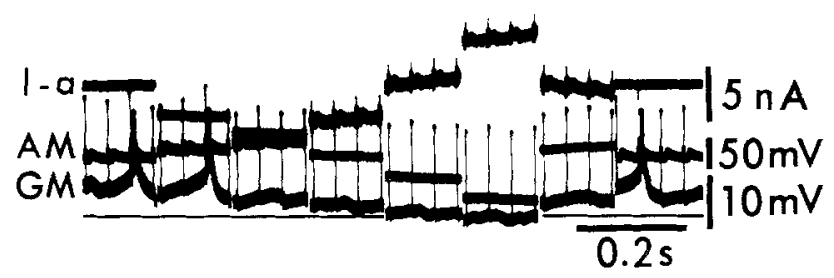

Fig. 10. Pair II. Presynaptic membrane potential and amplitude of postsynaptic IPSP. Simultaneous intracellular recording from presynaptic AM neuron (trace AM) and postsynaptic GM neuron (trace GM) while passing depolarizing current through AM neuron (trace I-a). Antidromic stimulation of $A M$ neuron continued throughout at $21 \mathrm{~Hz}$. Applied current was smoothly increased from 0 to about $12 \mathrm{nA}$ over a period of about 6 seconds and then as slowly reduced to 0 . Six segments of continuous records taken at regular intervals during the depolarizing phase are followed by two segments at longer intervals taken during the depolarizing phase. Reference line added. Note antidromic action potentials in AM trace, and smooth inerease in membrane potential of postsynaptic GM neuron as amplitude of summating IPSP increases. Individual AM neuron IPSP can be detected between stimulus artifacts in the fourth through sixth segments

and it was impossible to look for postsynaptic inhibitory or hyperpolarizing effects in the absence of presynaptic impulses.

All observations on interactions between this pair of neurons are consistent with the hypothesis proposed to account for the properties of PD-PY interaction, i.e., that release of inhibitory transmitter from the presynaptic terminal upon arrival of an action potential is facilitated by additional depolarization such 
as might be caused by synaptic or other graded, non-propagated potentials in neuropil arborizations of the presynaptic neuron. Indeed, our experiments suggest that under certain conditions such facilitation is a prerequisite for effective transmission.

The continuously graded increase in the potency of the AM synapses argues against the hypothesis that depolarization of the AM neuron causes antidromic impulses to invade AM processes (synapsing on GM neurons) that are not activated when the AM soma is at its resting potential. Such a mechanism might be expected to result in stepwise changes in synaptic potency as more branches are recruited rather than the continuous changes observed.

\section{Large EPSP Neuron-Lateral Cardiac or Posterior Gastro-Pyloric Neuron (EX-LC/GP Pair) \\ IV. Large EPSP Neuron-Gastric Muscle Neuron (EX-GM Pair)}

The two remaining neuron pairs will be considered together because they share one member. The shared neuron is unusual in that it has not been observed to produce true action potentials, even with extensive soma depolarization, nor has it yet been activated antidromically by stimulation of the stomatogastric nerve which contains its axon. It does, however, exhibit large depolarizing EPSPs (as well as smaller IPSPs) following stimulation of afferent interneuron axons in the stomatogastric nerve. This cell is termed the large EPSP or EX neuron. The EX neuron acts on the GM neurons and another neuron which is either the one innervating the interior lateral cardiac muscles (the LC neuron), or the one innervating the intrinsic posterior gastric pyloric muscle (the GP neuron). Since identification is uncertain, this cell will be termed the LC/GP neuron for purposes of this paper only. The neuron pairs are therefore III, the $\mathrm{EX}-\mathrm{LC} / \mathrm{GP}$ pair and IV, the EX-GM pair.

Fig. 11 is taken from a preparation in which simultaneous intracellular recordings were obtained from the EX neuron, the LC/GP neuron, and a GM neuron. The remaining traces record extracellular potentials in the lateral ventricular nerve, the anterior median nerve, and the stomatogastric nerve. In the typical, unstimulated preparation, the EX cell is inactive, the LC/GP neuron is likewise inactive but receives continuous inhibitory bombardment from the CI neuron and the GM neuron is either inactive, as here, or discharges repetitively on a background of IPSPs from the CT neuron. Upon repetitive stimulation of interneuron axons in the stomatogastric nerve, EPSPs and IPSPs occur in all three elements, with predominantly excitatory effects in the $\mathrm{EX}$ and LC/GP neurons and inhibitory effects in the GM neuron. After cessation of stimulation, how ever, and consequent reduction in inhibitory input, all three elements show a slow depolarization which often takes tens of seconds to return to the prestimulus baseline (Fig. 11A).

Fig. 11B illustrates the connections of primary interest between the EX and the LC/GP and GM neurons. Depolarization of the EX cell-which does not produce an action potential-evokes prolonged hyperpolarization in the LC/GP and the GM neurons. The responses of the two postjunctional elements differ somewhat. The hyperpolarization recorded in the LC/GP neuron decays over time,

16 J. comp. Physiol., Vol. 97 


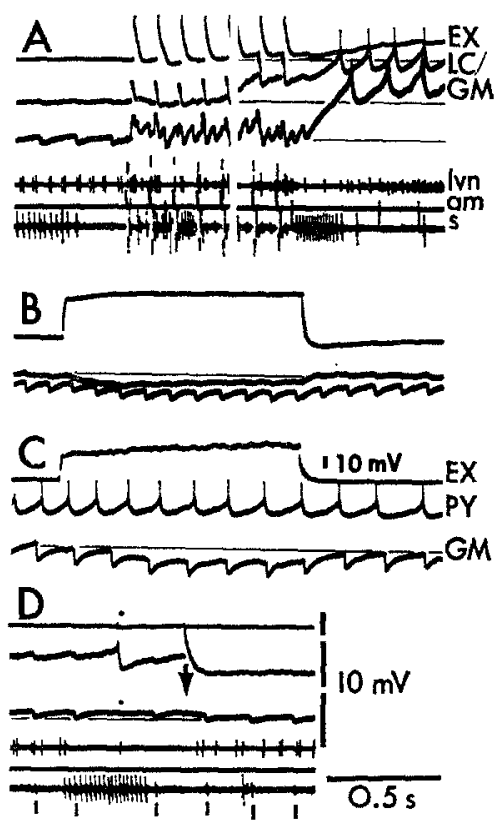

Fig. 11A-D. Pairs III and IV. Interactions of large EPSP, lateral cardiac/gastropyloric and GM neurons. Response to synaptic activation

(A) Intracellular recording from EX neuron (trace EX), LC/GP neuron (trace LC), GM neuron (trace GM) and extracellular recording from lateral ventricular nerve (trace s). All three penetrated units initially quiescent with IPSPs from CI neuron evident in LC/GP and GM elements. At $0.5 \mathrm{sec}$, stimulated stomatogastric nerve (at about $10 \mathrm{~Hz}$ ) close to esophageal ganglion (see Fig. 1 for approximate position of stimulating electrodes). Each input volley evoked a large EPSP in the EX neuron and EPSPs followed by IPSPs in the LC/GP and GM neurons. 2.5 seconds of continuous stimulation was removed from the record. After termination of stimulation, poststimulus depolarization in all three neurons reached several $\mathrm{mV}$ and took several tens of seconds to return to prestimulus membrane potential levels.

(B) Effect of depolarization of EX neuron on LC/GP and GMI neurons. Intracellular recordings from EX, LC/GP and GM neurons in order. About 2 sec depolarization of $\mathrm{EX}$ neuron produces hyperpolarization (NSI) of both GP and GM neurons.

(C) Effect of depolarization of EX neuron on PY and GM neurons (Pair IV). Depolarization of EX neuron was without effect on PY neuron (trace PY) but hyperpolarized the GM element.

(D) Effect of depolarizing LC/GP neuron on GM neuron. Recording traces as in Fig. $11 \mathrm{~A}$. Depolarizing current in LC/GP unit turned off at arrow. Action potential in LC/GP neuron evokes small IPSP in EX and GM neurons (see dots), and inhibits CI discharge (longer interval between CI neuron IPSP). Depolarization of LC/GP neuron also depolarizes GM neuron, indicating an electrical junction (see also Fig. 12). Vertical lines below "s" trace identify CI neuron action potentials.

Current-recording electrodes were not balanced so that apparent membrane potential deflections of cell depolarized by current may be inaccurate in both sign and amplitude. Reference line added

and upon cessation of EX depolarization is followed by a transient depolarization. The GM neuron does not show such a decay, and for this reason the EX neuron is assumed to have a direct effect on GM. Fig. $11 \mathrm{C}$ is taken from another 
preparation to show that depolarization of the EX neuron has no effect on one of the PY neurons, although the GM element is hyperpolarized. In these interactions, therefore, the presynaptic cell does not produce action potentials-in fact, it may be incapable of producing them (see Chappel and Dowling, 1972)but nevertheless produces hyperpolarization in postjunctional elements when depolarized.

The above connections, however, are not the only ones that exist between the three kinds of neurons, EX, GM and LC/GP. Fig. $11 \mathrm{D}$ shows that the LC/GP and the GM are electrically coupled (see also Fig. 12), and that the LC/GP makes typical inhibitory synapses with both the EX and the GM neurons. Each LC/GM impulse evokes a small IPSP in the two postsynaptic neurons. The LC/GP neuron must also form inhibitory connections with the CI neuron, because the latter's discharge frequency is slowed or stopped when and only when spikes appear in the LC/GP neuron.

Since the inhibitory effects of the EX neuron do not appear to require mediation by action potentials, we have termed the phenomenon "non-spike inhibition" (NSI) to differentiate it from inhibitory potentials associated with action potentials in the presynaptic element. This distinction is not intended to imply different mechanisms acting at the junction, but rather to emphasize that different types of activity in the presynaptic neuron are capable of mediating effective junctional transmission. Several of its properties are consistent with the supposition that NSI results from release of a transmitter agent from the prejunctional EX neuron. Fig. 12 illustrates the effects of one second current pulses, both depolarizing and hyperpolarizing, in the prejunctional EX cell and the postjunctional LC/GP element. Pulses were applied at different intervals following a 2.5-3.1 sec activation by stomatogastric nerve stimulation (see Fig. 11 A), and accordingly occurred over a range of pre- and postjunctional membrane depolarizations. Several results are evident:

1) Only depolarizing current in the EX neuron evokes the NSI; hyperpolarizing current is without significant effect (Fig. 12B).

2) The amplitude of the NSI is an apparent function of postjunctional membrane potential (Fig. 13). This relationship remains somewhat in doubt, however, because changes in membrane potential and an increase in membrane conductance of the prejunctional neuron paralleled postjunctional membrane potential changes. Current injected into the GM neuron induced membrane potential changes and increased the size of CI neuron IPSPs. However, such current was much less effective in increasing NSI amplitude than were synaptically induced depolarizations (Fig. 13). This is what one would expect to observe if attenuation of current from the soma into the region of NSI action were greater than attenuation of current from the synaptic sites.

3) Neither hyperpolarization nor depolarization of the postjunctional GM neuron produces a significant effect on the EX neuron (Fig. 14).

4) Impulses in the LC/GP neuron initiated by depolarizing currents evoke summating IPSPs in the EX neuron although the depolarization itself and hyperpolarization have no significant effect on the EX cell. 


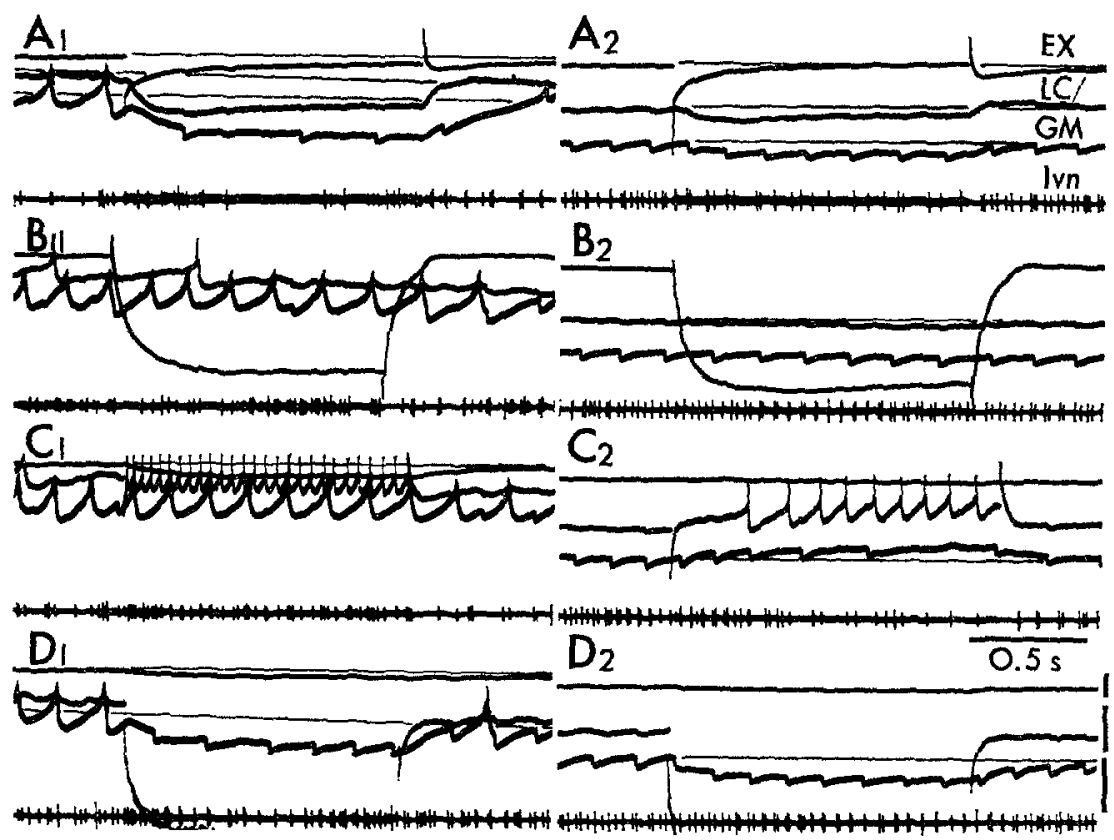

Fig. 12A-D. Pairs III and IV. Effect of membrane potential and polarity of injected current on postjunctional elements

Column 1, records taken $2.5-3 \mathrm{sec}$ after a period $(2.5-3 \mathrm{sec})$ of stomatogastric nerve stimulation at about $10 \mathrm{~Hz}$ (see Fig. 11 A). Column 2, records taken when membrane potentials of the three penetrated neurons had recovered to a common level of depolarization (e.g., 7.5-16.7 see after record of Column 1). Trace EX from the EX neuron, trace LC/ from the LC/GP neuron, trace GM from the GM neuron, and trace lvn from the lateral ventricular nerve. Current applied to EX neuron, approximately $\pm 5 \mathrm{nA}$, current applied to LC/GP neuron, approximately $\pm 8 \mathrm{nA}$.

(A) Depolarization of EX neuron produces NSI in LC/GP and GM neurons. Note: a) positive relation between amplitude of membrane potential and amplitude of hyperpolarization, b) tendency of NSI in LC/GP neuron to decay over time and "overshoot" following cessation of current flow in prejunctional unit, c) shift of balance of EX neuron indicating lower membrane resistance associated with greater depolarization in $A_{1}$ than in $A_{2}$. (B) Hyperpolarization of EX neuron produces none or only slight potential changes in LC/GP or GM neurons. (C) Depolarization of LC/GP neuron initiates repetitive action potentials which inhibit the EX neuron (see C1) and the CI neuron (see C2), and produce small IPSPs in the GM neuron which partially counteract the maintained depolarization resulting from current flow in the prejunctional elements. (D) Hyperpolarization of LC/GP neuron eauses significant hyperpolarization of the GM element, but slight, if any, hyperpolarization of the EX neuron. Voltage calibrations, $10 \mathrm{mV}$; reference lines added

5) Both hyperpolarization and depolarization of the LC/GP neuron were reflected by corresponding but attenuated shifts in the membrane potential of the GM neuron, as expected with an electrically coupled pair.

If the NSI is mediated by a transmitter, then blocking agents such as picrotoxin might abolish the hyperpolarizing effect. Fig. 15 illustrates the results of an experiment in which the ganglion was bathed with $10^{-4} \mathrm{M}$ picrotoxin. Records 


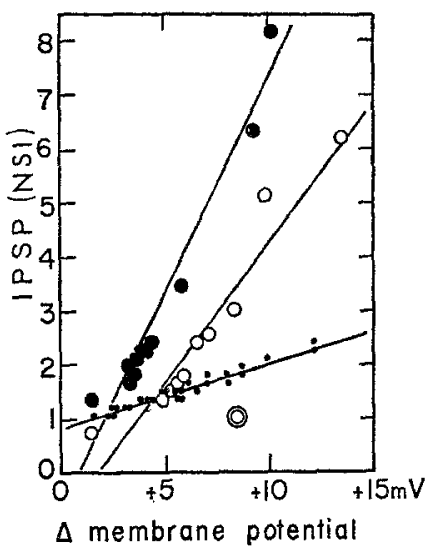

Fig. 13. Pairs III and IV. Relation between amplitude of postjunctional non-spike inhibition and IPSP and depolarization of postjunctional unit. Ordinate, amplitude in $\mathrm{mV}$ of hyperpolarizing NSI (nonspike inhibition potential) or IPSPs in GM neuron. Abscissa, depolarizing shift from resting level of membrane potential recorded in GM neuron soma. Small dots, · CI neuron IPSPs in GM neuron, depolarization produced by stomatogastric nerve stimulation and by injected current. Open circles, $O$ NSI in GIC neuron, depolarization produced by stomatogastric nerve stimulation only. Open double circle, $\odot$ NSI in GM neuron, depolarization produced by injected current only. Closed circles, • NSI in LC/GP neuron, depolarization produced by stomatogastric nerve stimulation only. Data taken from preparation illustrated in Fig. 12

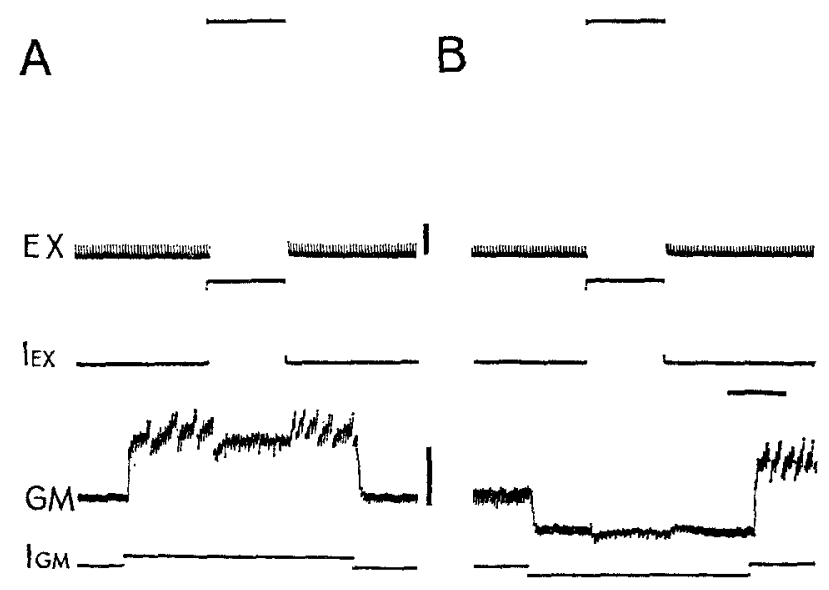

Fig. 14A and B. Pair IV. Effect of depolarization and hyperpolarization of GM. Simultaneous intracellular recording from EX neuron (trace EX) and GM neuron (trace GM). $\mathrm{I}_{\mathrm{EX}}$ current passed into EX neuron, $I_{G M}$ current passed into GM neuron. Initially, EPSPs are seen in the

EX neuron and IPSPs from the CI neuron are seen in the neuron

(A) Depolarization of GM neuron has no effect on either the membrane potential or the EPSP frequency in the EX neuron. Depolarization of the EX neuron during GM depolarization, however, hyperpolarizes the GM neuron. (B) Hyperpolarization of the GM neuron has no effect on either the membrane potential or the EPSP frequency in the EX neuron. EX depolarization during GM hyperpolarization further hyperpolarizes the GM neuron 

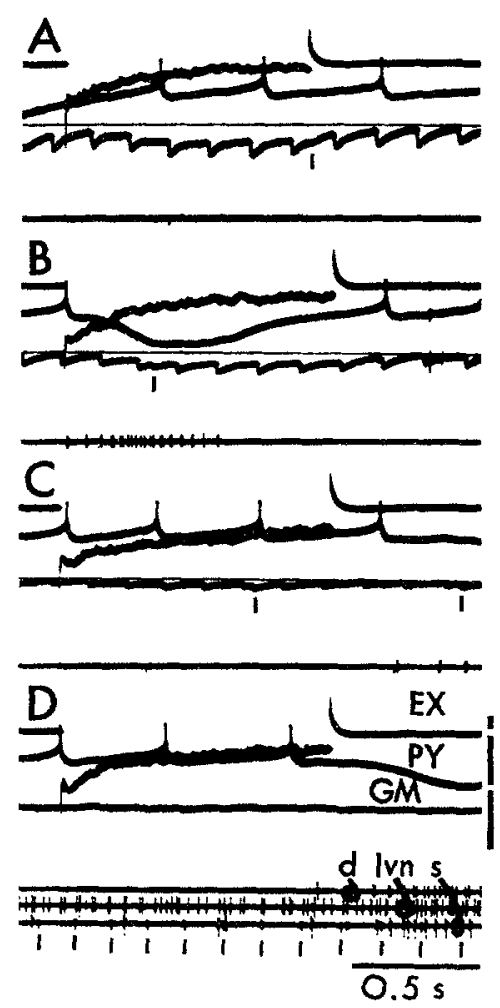

Fig. 15A-D. Pair IV. Effect of picrotoxin on NSI in GM neuron. Intracellular records from EX neuron, PY neuron, and GM neuron, extracellular records from ventral pyloric dilator nerve (d) in records $A, B$, and $C$. In $D$, two additional extracellular traces are included, one from the lateral ventricular nerve (lvn) and one from the stomatogastric nerve (s). EX neuron depolarized by injected current for about 1 sec in each record

(A) Before picrotoxin, normal NSI in GM neuron, no response in PY neuron. Vertical hatch mark indicates small IPSP in GM neuron which was not produced by CI neuron. (B) Picrotoxin, $10^{-4}$ M, 81 sec after first application. Reduced amplitude of NSI and CI neuron IPSP, but no effect on small IPSP in GM neuron (vertical hatch mark) or IPSPs in PY neuron produced by PD neuron burst (refer to Figs. 3-6). (C) Picrotoxin, 10 $0^{-4} \mathrm{M}, 140$ sec after introduction. Much reduced NST and CI neuron IPSP. No effect on small IPSP (vertical hash marks). (D) Picrotoxin, 10-4 M, 211 sec after picrotoxin perfusion began. Complete block of NSI and CT neuron IPSP. IPSPs in PY neuron produced by PD burst appear unaffected. Vertical hatch marks below "s" trace identify CI neuron action potentials, indicating that it continues to discharge at its normal, regular frequency. Voltage calibration, $10 \mathrm{mV}$; reference lines added

were taken at intervals after application began. The picrotoxin did not produce significant changes in membrane potential in either the EX neuron or the postjunctional GM element. The shift in balance of the current electrode, however, indicates a slight increase in EX conductance. The most prominent effect of picrotoxin was the parallel of IPSPs from the CI neuron and the NSI. Picrotoxin had no obvious effect on the discharge of the PY unit or upon the inhibition associated with the PD neuron bursts (see Fig. 3-6). Nor did it affect the dis- 


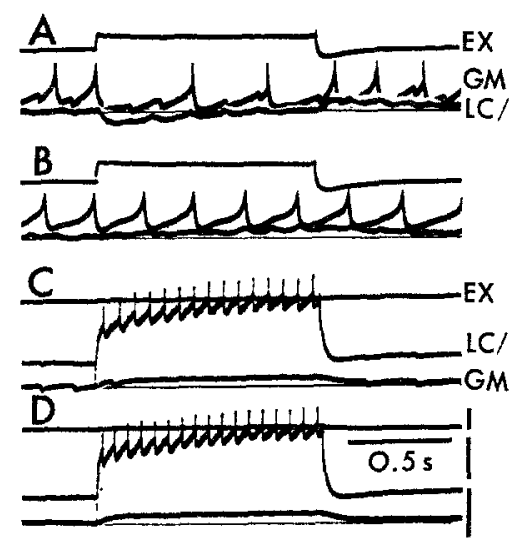

Fig. 16A-D. Pair III. Effect of picrotoxin on NSI in LC/GP neuron. EX neuron depolarized by injected current for about 1 sec in records (A) and (B); LC/GP neuron depolarized in records (C) and (D). Records selected for comparable membrane potentials in the penetrated units

(A) Normal response, before picrotoxin. Note "phasic" nature of NSI in LC/GP and depolarization upon cessation of current flow in $\mathrm{EX}$ neuron. $G M$ neuron record partially erased to emphasize LC/GP response. (B) Picrotoxin, $10^{-4} \mathrm{M}, 5 \mathrm{~min}+$ wash. The NSI in the GM neuron and the hyperpolarizing portion of the LC/GP response are completely blocked. The time course of depolarization remaining in the LC/GP neuron approximates the NSI "decay" observed in Figs. 11 B, 12A, and 15 A. Amplitude differences in EX neuron response to depolarizing current in (A) and (B) reflect small changes in neuron resistance caused by picrotoxin. (C) Normal effect of depolarization of LC/GP neuron on GM element. (D) Picrotoxin, $10^{-4} \mathrm{M}$, after more than $7 \mathrm{~min}$ wash. Complete block of CI neuron IPSP; interaction between LC/GP neuron and GM neuron was not significantly changed. Voltage calibration, $10 \mathrm{mV}$; reference lines added

charge of the CI neuron, only its inhibitory effect on GM. And finally, picrotoxin did not grossly affect the amplitude or time course of small IPSPs in the GM neuron originating in an unknown element (see Fig. 15A, 15B, and 15C). Fig. 16 shows the results of a similar experiment in the preparation with records from the LC/GP and the GM neuron. Although the hyperpolarizing NSI is abolished, a slow depolarization, which may be responsible for the apparent decay mentioned in Fig. $11 \mathrm{~A}$, remains in the LC/GP neuron after complete block of all hyperpolarization. Fig. $16 \mathrm{~A}$ and $16 \mathrm{~B}$ also show that the increase in $\mathrm{EX}$ conductance following synaptic activation may be greater than that associated with any changes produced by picrotoxin, as measured in the cell body. The lack of effect of picrotoxin on the strength of LC/GP neuron-GM neuron coupling (Fig.16C, $16 \mathrm{D})$, together with the preceding observations, indicates that the picrotoxin effect on the NSI probably cannot be ascribed to a generalized or nonspecific action on pre- or postsynaptic membrane properties. Our results are consistent with the classical view (Robbins and Van der Kloot, 1958; Grundfest el al., 1959) that picrotoxin blocks inhibitory transmission in crustacea by action at the postsynaptic membrane receptor site.

Without a complete study, however, interpretation of drug effects on a new preparation is always hazardous. In order to provide further perspective, the 

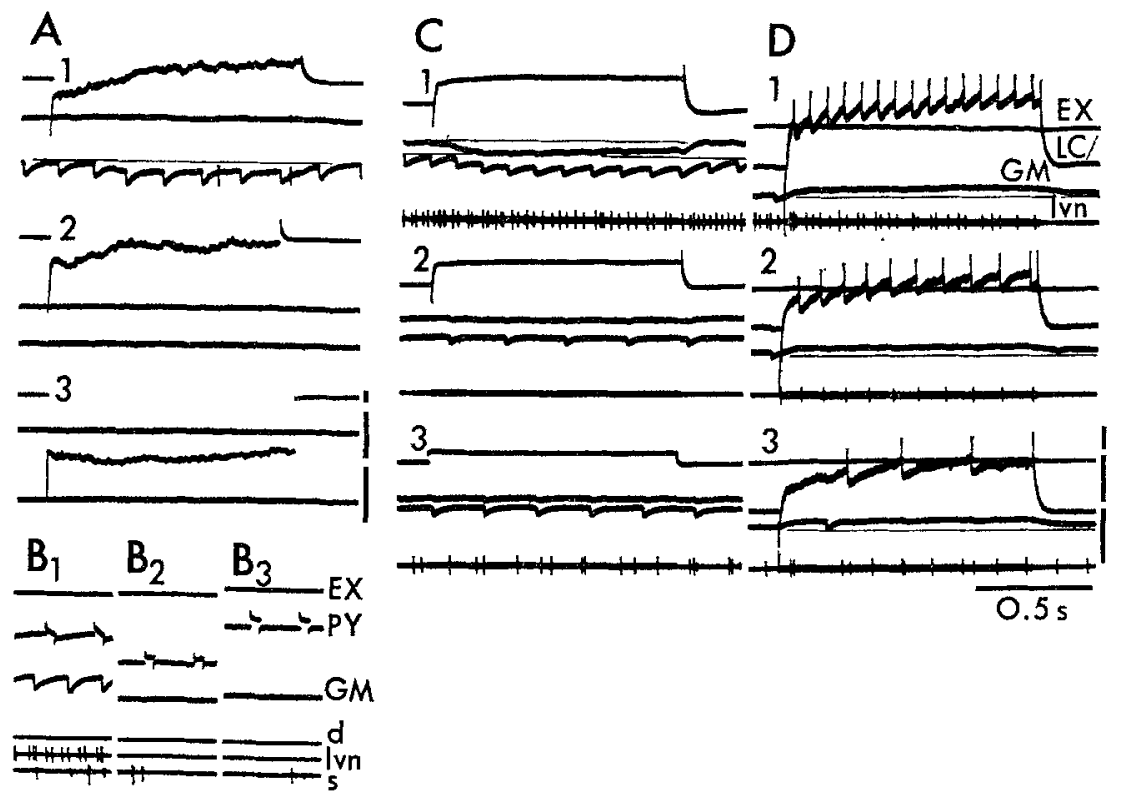

Fig. 17A-D. Effects of L-glutamate and GABA on EX, PY, LC/GP and GM neurons

(A) Intracellular records from EX, PY, and GM neurons; the EX neuron was depolarized for about 1 sec. 1) normal; 2) 1 -glutamate, $5 \times 10^{-3} \mathrm{M}$, after $90 \mathrm{sec}$; 3) $\mathrm{GABA}, 5 \times 10^{-3} \mathrm{M}$, after 90 sec. GABA greatly reduced resistance of EX neuron. Both glutamate and GABA block all CI neuron activity in this preparation.

(B) Intracellular records as above, but arranged to show directions and amplitude of membrane potential shifts for all three neurons, and changes in apparent membrane resistance for the PY neuron. 1) normal ; 2) 1-glutamate, $5 \times 10^{-3} \mathrm{M}$, after $90 \mathrm{sec}$; 3) GABA, $5 \times 10^{-3} \mathrm{M}$, after 90 sec. The EX neuron was depolarized by both glutamate and GABA, but the GABA effect was greater. The PY neuron membrane conductance increased with both glutamate and GABA, but this was associated with hyperpolarization after glutamate and depolarization after GABA. The GM neuron was hyperpolarized with glutamate and to a lesser extent with GABA. Almost all discharge activity recorded in extracellular traces ( $d$ ventral pyloric dilator nerve, $l v n$ lateral ventricular nerve, $s$ stomatogastric nerve) was blocked.

(C) Intracellular records from EX, LC/GP, and GM neurons and extracellular records from the lateral ventricular nerve (lvn). The EX neuron was depolarized for about 1 sec. 1) normal; 2) 1-glutamate, $5 \times 10^{-3} \mathrm{M}$, after $60 \mathrm{sec}$; 3) $\mathrm{GABA}, 5 \times 10^{-3} \mathrm{M}$, after 90 sec. Nearly complete block of NSI followed glutamate and complete block followed GABA. The great increase in EX neuron conductance following GABA was indicated by the reduction in amplitude and time course of potential change produced by injected current. The reduction in amplitude of CT neuron IPSP was concomitant with hyperpolarization of LC/GP and GM neurons. The discharge recorded in Ivn trace was reduced.

(D) Intracellular records as in (C), but with depolarization of LC/GP neuron. 1) normal; 2) 1-glutamate, $5 \times 10^{-3} \mathrm{M}$, after $20 \mathrm{sec}$; 3) after GABA, $5 \times 10^{-3} \mathrm{M}, 43$ sec. Although the spike discharge of the LC/GP neuron changes, there was no significant change in depolarization in GM neuron

Voltage calibrations, $10 \mathrm{mV}$ (those of $A_{3}$ apply to all $A$ and $B$ records; those of $D_{3}$ apply to the remainder). Reference lines added 
effects of two substances whose actions are blocked by picrotoxin in this preparation, 1-glutamate and gamma-aminobutyric acid (GABA), are illustrated in Fig. 17. Unlike picrotoxin, both glutamate $\left(5 \times 10^{-3} \mathrm{M}\right)$ and GABA $\left(5 \times 10^{-3} \mathrm{M}\right)$ caused significant depolarization of the EX neuron and an increase in transmembrane conductance; GABA is the more effective. Glutamate and GABA also caused hyperpolarization of both the LC/GP neuron and the GM neuron with consequent reduction in amplitude of CI-induced IPSPs. The reduction in time course of such IPSPs in the GM neuron suggests that an increase in conductance accompanied the hyperpolarization. The action of the two agents on the PY neuron, although not immediately relevant, is mentioned because of the divergent effects observed. Both glutamate and GABA caused an increase in PY conductance, but this was associated with hyperpolarization with glutamate and depolarization with GABA. Neither glutamate nor GABA appear to have appreciable effect on the coupling strength of the LC/GP-GM neurons. The NSI, however, is greatly reduced (glutamate, Fig. 17C2) or absent. Significantly, both the hyperpolarizing and the depolarizing effects (which remained after picrotoxin treatment) disappeared. The results of Fig. 17 suggest that the loss of NSI following glutamate or GABA is best explained by a combination of increased conductance in both pre- and postjunctional elements resulting in reduced spread of current from or to the recording/stimulating electrode in the soma, and movement of the membrane potential toward the NSI equilibrium potential, which results in smaller NSI (Fig. 12 and 13). Obviously other factors such as postmembrane receptor desensitization could also be involved without being detected in these experiments. Whatever the mechanism, however, the important point is that picrotoxin block of NSI was quite different from that observed in Fig. 17:

1) it occurred without major detectable changes in membrane potential or membrane conductance; 2) it paralleled block of CI-induced IPSPs; and 3) only the hyperpolarizing component of the NSI in the LC/GP element was abolished. It would be difficult to account for these and the other characteristics of the NSI in terms of current flow and electrical mechanisms only, but they are all consistent with the hypothesis that the NST occurs as the result of the release of a transmitter agent from the prejunctional terminal.

\section{Diseussion}

These experiments suggest that synaptic transmission in a neuropil can be significantly modified by local variations in the presynaptic membrane potential such as might occur via electrotonic spread from nearby sites of postsynaptic or pacemaker activity. Since such modulations, if generally present, would be important in neural integration, it is appropriate to review the evidence which leads to this conclusion and to indicate possible alternative explanations of our data.

The basic experimental phenomenon-facilitation of inhibitory synaptic transmission or production of postjunctional hyperpolarization by depolarization of the presynaptic cell body-seems firmly established. The effect was specific, occurred repeatedly without any indication of interneuron action potentials (in one instance, pair II, the junction was clearly monosynaptic) and disappeared when the current electrode was withdrawn from the presynaptic neuron. Intra- 

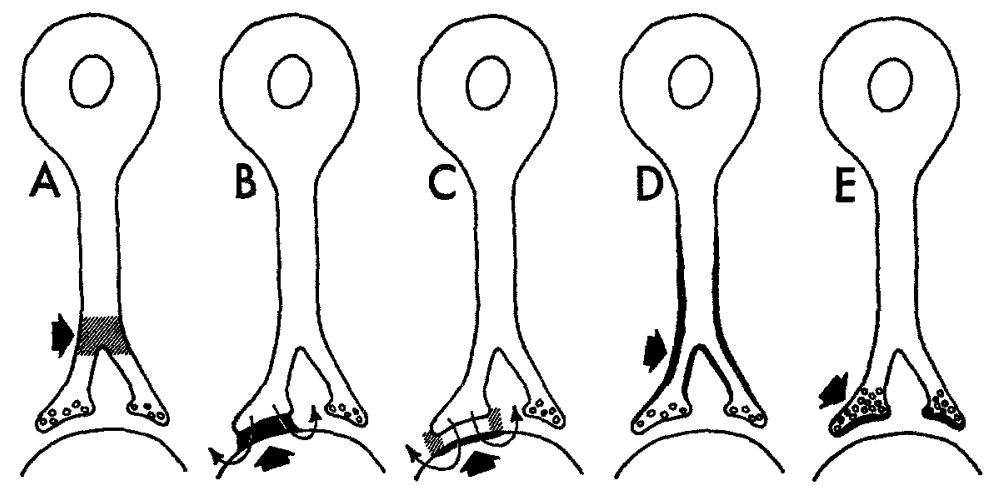

Fig. 18 A-E. Alternative mechanisms of synaptic facilitation by presynaptic depolarization

(A) Facilitation of action potential spread into telodendria. Arrow indicates possible region of impulse blockage. (B) Spread of depolarizing current across low resistance junction into postsynaptic element. Arrow indicates electrical junction which lies near chemical junction. (C) Depolarizing eurrent in prejunctional element is guided across high resistance membrane in postjunctional unit (arrow), thus producing focus of hyperpolarization. (D) Amplitude of prejunctional action potential is augmented, thus increasing transmitter release. (E) Transmitter release is directly facilitated by depolarizing current flow in region of telodendria

cellular penetrations were stable for the duration of the experiments, e.g., 2-3 hours or more, and the effect was highly reproducible.

The mechanism underlying the phenomenon is important, and five alter natives can be considered (Fig. 18).

I. Depolarization of the cell body facilitates transmission of the action potential across regions of low safety factor in the neuropil ramifications, and thus permits the effective presynaptic trigger, the action potential, to reach presynaptic terminals (Fig. 18 A).

II. Depolarizing current spreads, via a low resistance junction, into the postsynaptic element, causing depolarization and consequent increase in the size of the IPSP produced by a given dose of transmitter (Fig. 18B).

III. Depolarizing current spreads along processes of the presynaptic element, out the prejunctional membrane, and inward through the postjunctional element, causing hyperpolarization of the postjunctional membrane (see Brooks and Eccles, 1947) (Fig. 18C).

IV. Depolarization of the cell body causes an increase in the amplitude and/or duration of the action potential at the presynaptic terminal (mechanism unspecified), thus increasing the amount of transmitter released (Brooks and Eccles, 1947) (Fig. 18D).

V. Polarization of the presynaptic terminal, caused by spread from the cell body or presynaptic region, induces direct release of transmitter (NSI), or so alters the ending that the arriving action potential releases a greater amount of transmitter per impulse (Fig. 18E). 
Let us consider each of these alternatives in the light of our results.

I. The first alternative, in which the action potential crosses more regions of low safety factor, provides an inadequate mechanism since it does not account for observed effects in the absence of presynaptic spikes (pairs I, III and IV), and it does not easily provide a mechanism for continuously graded effects as observed in pair II. A great many regions of low safety factor would be required to obscure a stepwise increase in synaptic effectiveness as each axonal branch is recruited.

II. The second alternative, increase of IPSP amplitude resulting from depolarization of the postsynaptic unit, is in direct conflict with the postsynaptic inhibition and hyperpolarization observed in pairs I, III and IV in the absence of presynaptic spikes. Moreover, an increase in the excitability of the postsynaptic unit would be expected to accompany depolarization. However, we observed no change in spike frequency when assumed depolarizing and hyperpolarizing effects were added in pair II. Nor does such a mechanism explain the observed increase in IPSP amplitude with hyperpolarization in pair III. Finally, no direct evidence of such an effect in the form of appropriate membrane potential changes during prejunctional depolarization was observed.

III. The third alternative, postjunctional hyperpolarization caused by presynaptic depolarization producing inward postjunctional current without transmitter mediation, also seems unlikely. There is no obvious structural or geometrical specialization such as might be expected (see Furshpan and Furukawa, 1962) to channel current across the postjunctional membrane. Furthermore: a) postjunctional membrane potential shifts are not apparent in the prejunctional elements; b) hyperpolarization of the postsynaptic unit should and does cause a decrease in the size of the IPSP (as shown by direct experiment, e.g., Fig. 12D), whereas an increase in IPSP size was observed in pairs I and II during prejunctional depolarizations (Fig. 5, 8, 10) in pair I presynaptic hyperpolarization reduced the IPSP without associated postjunctional membrane potential changes (Fig. 5); d) in pairs III and IV the amplitude of the NSI was abolished by picrotoxin, leaving, in pair III, an underlying slow depolarization (Figs. 15, 16).

The reasons for discarding this mechanism seem entirely convincing for pairs I and II, but perhaps more indirect for pairs III and IV. However, there are important similarities among the phenomena observed in the various pairs, such as postsynaptic hyperpolarization without presynaptic spikes in pairs I, III and IV. In addition, at least three unusual electrical properties would be required to account for the experimental observations on pairs III and IV: 1) undirectional current flow from pre- to postjunctional unit with complete absence of effective current flow, inward or outward, from post- to prejunctional unit; 2) special, localized changes in membrane properties accounting for the relation between NSI and postneuron membrane potential; and 3) specific sensitivity to picrotoxin of the NSI current flow. These considerations seem sufficient reason to consider this alternative highly improbable for all four pairs.

IV. The fourth alternative, increased transmitter release resulting from a larger or longer presynaptic action potential, represents a mechanism akin to alternatives $I$ and $V$, but differs in that it places the entire load on the amplitude 
and/or duration of the action potential in the terminal, not on its presence or absence (alternative I) and not on its interaction with subthreshold terminal potential shifts (alternative $V$ ). As with alternative $I$, this mechanism alone cannot account for effects in the absence of spikes, and where increased spike amplitudes were observed in the cell body (produced by hyperpolarizing, not depolarizing presynaptic neuron current) they produced smaller rather than larger IPSPs (Fig. 5), exactly the opposite of the effect predicted by this mechanism. Although we cannot deny the possibility that changes in spike form, duration, or amplitude at the terminal are associated with variations in transmitter release, alternative IV, which does not include the possibility of transmitter release without spikes, is inadequate.

$\mathrm{V}$. We are left, therefore, with the fifth alternative, that the observed effects are best explained by assuming direct action of the current on the presynaptic terminal, causing an increased release of transmitter. That depolarization itself is sufficient to cause transmitter release has been reported for the neuromuscular junction (del Castillo and Katz, 1954; Katz and Miledi, 1965, 1967; Liley, 1950) and for the squid giant synapse (Bloedel et al., 1966; Katz and Miledi, 1966). This accounts for all the reported observations, and involves processes similar to those known in other preparations (Kennedy and Mellon, 1964). It is possible that some mechanism such as this may explain observed failures of antidromic impulses to evoke the kind of postsynaptic effects that follow normal orthodromic impulses in insect neuropil (see Wilson, 1964), and crustacean ganglion (Mulloney and Selverston, 1972). In our preparation, however, we have little information on detailed mechanisms of augmented transmitter release or the nature of the hypothetical transmitters themselves. Two transmitters are suspected because the PY neuron IPSPs produced by PD elements are not blocked by picrotoxin the NSI in GM and LC/GP units as is (see Fig. 15).

An important question is whether the observed effects occur during normal ganglion function or appear only under circumstances of current flow or membrane potential which are never encountered under normal circumstances. This problem is best considered in two parts:

First. Are the observed effects due to some abnormal state of the isolated preparation? Since we do not have intracellular records from an intact preparation, this cannot be answered fully, but we can affirm that the observed pyloric discharge pattern is like that recorded in vivo in intact Homarus (Morris and Maynard, 1969) and like that observed in extracellular recordings from Panulirus nerves and muscles after much more rapid dissections (one hour or less) which left the ganglion system and stomach largely intact. From this we conclude that interaction in the pyloric system is relatively normal in the isolated preparation. The gastric mill neurons are more difficult to evaluate because a full, normal gastric mill rhythm was rarely observed in the isolated preparation. The reasons for this are unclear. Perhaps the process of dissection altered the state of the gastric mill neurons, or removed necessary sensory feedback, or perhaps the environment of the isolated preparation was inappropriate. Since, however, the gastric mill rhythm, unlike the pyloric rhythm, apparently occurs in the intact animal only under specifie circumstances (see Morris and Maynard, 1969), it presumably is called into action only on specific command by interneurons from the 
CNS. The absence of the gastric mill rhythm in the isolated preparation probably reflects the loss of appropriate afferent commands rather than significant alterations in the intrinsic properties of neurons. This view is supported by the work of Selverston and Mulloney (1974) who observed excitatory input to gastric neurons from cells in the commissural ganglia. Thus, there seems no reason to assume that isolation significantly alters the basic properties of ganglion neurons, inducing an abnormal state which permits the NSI phenomenon.

Second. Can the effects observed be produced by potential changes within the limits of those usually encountered in the ganglion? This question must be considered separately for each of the four neuron pairs described. In each case, precise quantitative measurements are impossible because the origin of most if not all local potential variations must lie in the neuropil at some unknown and possibly variable distance from the recording-stimulating electrode in the cell body. Arguments must therefore be indirect.

1) $\mathrm{PD}-\mathrm{PY}$ neuron pair. This pair provides the best evidence for a normal role of local presynaptic potentials in synaptic transmission. During the spontaneous burst, spike discharges arise from a slow potential shift of several millivolts (5-15 $\mathrm{mV}$ normally) as recorded in the cell body; this amplitude is probably larger in the neuropil. The size of IPSPs in the PY neuron produced by individual or repetitive orthodromic spikes during this slow potential shift is much greater than for IPSPs evoked by antidromic spikes at similar or higher discharge frequencies. The IPSPs induced by antidromic spikes, however, were augmented by depolarizing current which produced estimated PD potential changes of the same order of magnitude as did estimated normal shifts at short distances from the cell body.

2) AM-GM neuron pair. Under most circumstances in the isolated preparation the AM neuron was quiescent until synaptically activated. Summated potential shifts of several millivolts preceding repetitive discharges then occurred (potential changes of about $5 \mathrm{mV}$ and a maximum frequency of about $7 /$ sec were noted in the preparation described above). These values are just at the limits of effective presynaptic depolarization produced by injected current. If, however, this does not represent maximum AM neuron activity, our results suggest that in the fully activated cell, local depolarization will be well beyond threshold and that the effectiveness of synaptic transmission will be partially determined by such depolarization.

3) EX-GM neuron pair. In the typical preparation, EX neuron EPSPs, reached about $26 \mathrm{mV}$ with half-duration of $20 \mathrm{msec}$. Following presynaptic stimulation, depolarizing potential shifts of about $10 \mathrm{mV}$ remained for several seconds. These values are less than those produced in the cell body by injected current (calculated to be 50-60 $\mathrm{mV}$ ) which evoked significant NSI. The difference is not excessive, however, and if the sites of synaptic action are distant from the cell body, then summed depolarizations produced there by synaptic input must approximate current-induced depolarizations shown to be effective in evoking NSI. Unfortunately, methods of synaptically stimulating only the EX neuron without also producing input to the postjunctional $\mathrm{LC} / \mathrm{GP}$ and $\mathrm{GM}$ neurons have not been found and a direct demonstration of NSI by EX neuron EPSPs has not been possible. 
4) EX-LC/GP pair. The behavior of this pair does not differ significantly from that of the EX-GM pair, and need not be considered separately.

In summary, local synaptic or generator potentials recorded in attenuated form in the somas of the prejunctional elements of all four neuron pairs are generally no more than one order of magnitude smaller than current-induced soma depolarizations shown to evoke NSI or augmented IPSPs. If the effects of such prejunctional depolarizations occur at some distance from the cell body, in processes in the neuropil, then it seems highly probable that many local, nonspike potentials occurring during normal activity will be sufficiently large to modulate the release of transmitter.

Much recent thinking about integration in the central nervous system has assumed, either explicitly or implicitly, that communication between neurons normally involves a calculus of impulse intervals or spike frequency (see, e.g., Perkel and Bullock, 1968). In this view, an action potential, once initiated, does not convey information about its origin within the neuron. Thus, analyses of neural integration on an cellular level have focused on the relation between synaptic potentials and the initiation of specified action potential patterns in the neuron, i.e., these analyses assume that the significant input-output parameters of the neuron are summating EPSPs and IPSPs and spike potentials. In special instances, of course, other factors have been recognized, such as field potentials, electrical junctions between highly synchronized elements, transmission of excitation and inhibition in vertebrate and invertebrate retina without intervening action potentials, presynaptic inhibition, and so on. If our thinking about the present observations is correct, however, and if the phenomenon is of more than occasional or sporadic occurrence in integrating systems, then an additional factor must be considered in experimental analysis of neural integration and in attempts to develop functional models of the nervous system.

I wish to thank D. Kennedy and A. Selverston for their criticism of this manuscript; and D. Barker and S. Epstein for many helpful discussions. Supported by USPHS Grant Nos. N 506017 and NS 09474 to D. Maynard.

\section{Reforences}

Atwood, H. A., Maynard, D. M.: Divergent postsynaptic effects produced by a single motor neuron of the lobster stomatogastric ganglion. Am. Zool. 4, 248 (1969)

Bauman, F.: Slow and spike potentials recorded from retinula cells of the honeybee drone in response to light. J. Gen. Physiol. 52, 855 (1968)

Bentley, D. R.: Intracellular activity in cricket neurons during generation of song patterns. Z. vergl. Physiologie 62, 267-283 (1969)

Bloedel, J., Gage, P.W., Llinás, R., Quastel, D. M. J.: Transmitter release at the squid giant synapse in the presence of tetrodotoxin. Nature 212, 49-50 (1966)

Brooks, C. McC., Eccles, J. C.: An electrical hypothesis of central inhibition. Nature 159, 760-764 (1947)

Chappell, R. L., Dowling, J. E.: Neural organization of the median ocellus of the dragonfly. I. Intracellular electrical activity. J. Gen. Physiol. 60, 121-147 (1972)

Cole, W. H.: Saline for Homarus. J. Gen. Physiol. 25, 1-6 (1941)

Del Castillo, J., Katz, B.: Changes in end-plate activity produced by presynaptic polarization. J. Physiol. (London) 124, 586-604 (1954)

Dudel, J., Kuffler, S. W.: Presynaptic inhibition at the crayfish neuromuscular junction. J. Physiol. (London) 155, 543-562 (1961) 
Furshpan, E. J., Furukawa, T.: Intracellular and extracellular responses of the several regions of the Mauthner cell of the goldfish. J. Neurophysiol. 25, 732-771 (1962)

Grundfest, H., Reuben, J. P., Rickels, W. H., Jr.: The electrophysiology and pharmacology of lobster neuromuscular synapses. J. Gen. Physiol. 42, 1301 (1959)

Katz, B., Miledi, R.: Propagation of electric activity in motor nerve terminals. Proc. Roy. Soc., London, Ser. B 161, 453-482 (1965)

Katz, B., Miledi, R.: Input-output relation of a single synapse. Nature 212, 1242-1245 (1966)

Katz, B., Miledi, R.: The release of acetylcholine from nerve endings by graded electric pulses. Proc. Roy. Soc., London, Ser. B 167, 23-38 (1967)

Kennedy, D., Mellon, D.: Receptive-field organization and response patterns in neurons with spatially distributed input. In: Neural Theory and Modeling. R. F. Reiss (Ed.), 400-413. Stanford: University Press (1964)

Kennedy, D., Preston, J. B.: Activity patterns of interneurons in the caudal ganglion of the crayfish. J. Gen. Physiol. 43, 655-670 (1960)

Liley, A. W.: The effects of presynaptic polarization on the spontaneous activity at the mammalian neuromuscular junction. J. Physiol. (London) 134, 427-443 (1956)

Larimer, J. L., Kennedy, D. : Visceral afferent signals in the crayfish stomatogastric ganglion. J. Exp. Biol. 44, 345-354 (1966)

Maynard, D. M.: Integration in crustacean ganglia. Symp. Soc. Exp. Biol. 20, 111-149 (1966)

Maynard, D. M.: Discussion p. 61-68. In: The Interneuron. Brazier, M. A. B. (Ed.). UCLA Forum Med. Sci. No. 11. Los Angeles: Univ. of Calif. Press (1969)

Maynard, D. M.: Simpler Networks. Ann. New York Acad. Sci. 198, 59-72 (1972)

Maynard, D. M., Burke, W.: Electrotonic junctions and negative feedback in the stomatogastric ganglion of the mud crab, Scylla serrata. Am. Zool. 6, 4 (1966)

Maynard, D. M., Dando, M. R.: The structure of the stomatogastric neuromuscular system in Panulirus argus, Homarus americanus, and Callinectes sapidus (Decapod Crustacea). Proc. of the Royal Soc., London B. 268, 161-220 (1974)

Morris, J., Maynard, D. M.: Recordings from the stomatogastric nervous system in intact lobster. Comp. Biochem. Physiol. 33, 969-974 (1970)

Mulloney, B., Selverston, A.: Antidromic action potentials fail to demonstrate known interactions between neurons. Science 177, 69-72 (1972)

Mulloney, B., Selverston, A. I.: Organization of the stomatogastric ganglion in the spiny lobster. I. Neurons driving the lateral teeth. J. Comp. Physiol. 91, 1-32 (1974a)

Mulloney, B., Selverston, A. I.: Organization of the stomatogastrio ganglion in the spiny lobster. III. Coordination of the two subsets of the gastric system. J. Comp. Physiol. 91, 53-78 (1974b)

Orlov, J.: Das Magenganglion des Flußkrebses. Ein Beitrag zur vergleichenden Histologie des sympathischen Nervenkrosystems. Z. Mikrosk.-anat. Forsch. 8, 73-96 (1927)

Powers, L. W.: Gastrie mill rhythms in intact crabs. Comp. Biochem. Physiol. 46 A, 767783 (1973)

Robbins, J., Van der Kloot, W. G.: The effect of picrotoxin on peripheral inhibition in the crayfish. J. Physiol. (London) 143, 541 (1958)

Sehmidt, R. F.: Presynaptic inhibition in the vertebrate central nervous system. Ergeb. Physiol. 63, 20-101 (1971)

Selverston, A.I., Mulloney, B.: Organization of the stomatogastric ganglion in the spiny lobster. II. Neurons driving the medial tooth. J. Comp. Physiol. 91, 33-51 (1974)

Werblin, F. S., Dowling, J. E.: Organization of the retina of the mudpuppy, Necturus maculosus. II. Intracellular recording. J. Neurophysiol. 32, 339-355 (1969)

Wilson, D. M.: Relative refactoriness and patterned discharge of locust flight motor neurons. J. Exp. Biol. 41, 191-205 (1964)

Ms. Kerry D. Walton

Division of Neurobiology

University of Iowa

Oakdale, Iowa 52319, USA 